\title{
Luminescence dating and palaeomagnetic age constraint on hominins from Sima de los Huesos, Atapuerca, Spain
}

\author{
Lee J. Arnold ${ }^{a, *}$, Martina Demuro ${ }^{a}$, Josep M. Parés ${ }^{a}$, Juan Luis Arsuaga ${ }^{\text {b,c }}$, \\ Arantza Aranburu ${ }^{\mathrm{d}}$, José María Bermúdez de Castro ${ }^{\text {, }}$, Eudald Carbonell ${ }^{\mathrm{e}}$ \\ ${ }^{a}$ Centro Nacional de Investigación sobre la Evolución Humana, CENIEH, Paseo Sierra de Atapuerca s/n, 09002 Burgos, Spain \\ ${ }^{\mathrm{b}}$ Centro Mixto Universidad Complutense-Instituto de Salud Carlos III de Evolución y Comportamiento Humanos, Monforte de Lemos 3-5, Pabellón 14, 28029 \\ Madrid, Spain \\ ${ }^{c}$ Departamento de Paleontología, Facultad de Ciencias Geológicas, Universidad Complutense de Madrid, 28040 Madrid, Spain \\ ${ }^{\mathrm{d} D e p a r t a m e n t o ~ d e ~ M i n e r a l o g i ́ a ~ y ~ P e t r o l o g i ́ a, ~ F a c u l t a d ~ d e ~ C i e n c i a ~ y ~ T e c n o l o g i ́ a, ~ U n i v e r s i d a d ~ d e l ~ P a i ́ s ~ V a s c o . ~ A p . ~ 644, ~ 48080 ~ B i l b a o, ~ S p a i n ~}$ \\ 'Institut de Paleoecologia Humana i Evolució Social, Area de Prehistòria, U. Rovira i Virgili, Plaça Imperial Tarraco 1, E-43005 Tarragona, Spain
}

Keywords:

Geochronology

Middle Pleistocene

Brunhes

Western Europe

Homo heidelbergensis

Homo neanderthalensis

\begin{abstract}
A B S T R A C T
Establishing a reliable chronology on the extensive hominin remains at Sima de los Huesos is critical for an improved understanding of the complex evolutionary histories and phylogenetic relationships of the European Middle Pleistocene hominin record. In this study, we use a combination of 'extended-range' luminescence dating techniques and palaeomagnetism to provide new age constraint on sedimentary infills that are unambiguously associated with the Sima fossil assemblage. Post-infrared-infrared stimulated luminescence (pIR-IR) dating of K-feldspars and thermally transferred optically stimulated luminescence (TT-OSL) dating of individual quartz grains provide weighted mean ages of $433 \pm 15 \mathrm{ka}$ (thousands of years) and $416 \pm 19 \mathrm{ka}$, respectively, for allochthonous sedimentary horizons overlying the hominin-bearing clay breccia. The six replicate luminescence ages obtained for this deposit are reproducible and provide a combined minimum age estimate of $427 \pm 12$ ka for the underlying hominin fossils. Palaeomagnetic directions for the luminescence dated sediment horizon and underlying fossiliferous clays display exclusively normal polarities. These findings are consistent with the luminescence dating results and confirm that the hominin fossil horizon accumulated during the Brunhes Chron, i.e., within the last $780 \mathrm{ka}$. The new bracketing age constraint for the Sima hominins is in broad agreement with radiometrically dated Homo heidelbergensis fossil sites, such as Mauer and Arago, and suggests that the split of the $H$. neanderthalensis and $H$. sapiens lineages took place during the early Middle Pleistocene. More widespread numerical dating of key Early and Middle Pleistocene fossil sites across Europe is needed to test and refine competing models of hominin evolution. The new luminescence chronologies presented in this study demonstrate the versatility of TT-OSL and PIR-IR techniques and the potential role they could play in helping to refine evolutionary histories over Middle Pleistocene timescales.
\end{abstract}

\section{Introduction}

The endokarstic system of the Sierra de Atapuerca, north-central Spain, comprises an extensive network of cavities, passages and galleries spanning more than $4.7 \mathrm{~km}$ (Fig. 1). The 50 or so sedimentfilled cavities explored to date have yielded an unparalleled archive of Early to Late Pleistocene hominin remains, lithic tools and associated faunal assemblages (e.g., Arsuaga et al., 1993, 1997a, 1999; Carbonell et al., 1995; Carbonell, 2008; Bermúdez de Castro et al., 1997, 1999; Cuenca-Bescós et al., 2010; Rodríguez et al.,

\footnotetext{
* Corresponding author.

E-mail address: lee.arnold@cenieh.es (L.J. Arnold).
}

2011; Ollé et al., 2013). One of the most prolific palaeoanthropological sites discovered at Atapuerca is Sima de los Huesos or the 'Pit of Bones' (herein abbreviated to 'Sima'), a small phreatic chamber in the lowest level of the Cueva Mayor-Cueva del Silo karst system, located $>500 \mathrm{~m}$ from the cave entrance of Cueva Mayor and $\sim 35 \mathrm{~m}$ below the present-day surface (e.g., Arsuaga et al., 1997a; Ortega et al., 2013) (Figs. 1 and 2a and b). The site is renowned for its unique accumulation of hominin fossils (Arsuaga et al., 1993, 1997a,b), which totals more than 6500 remains from at least 28 individuals (Bermúdez de Castro et al., 2004) and represents $\sim 80 \%$ of the global Middle Pleistocene fossil record for the genus Homo. This fossil collection grows in number with every excavation season, providing new opportunities to assess intra- and 


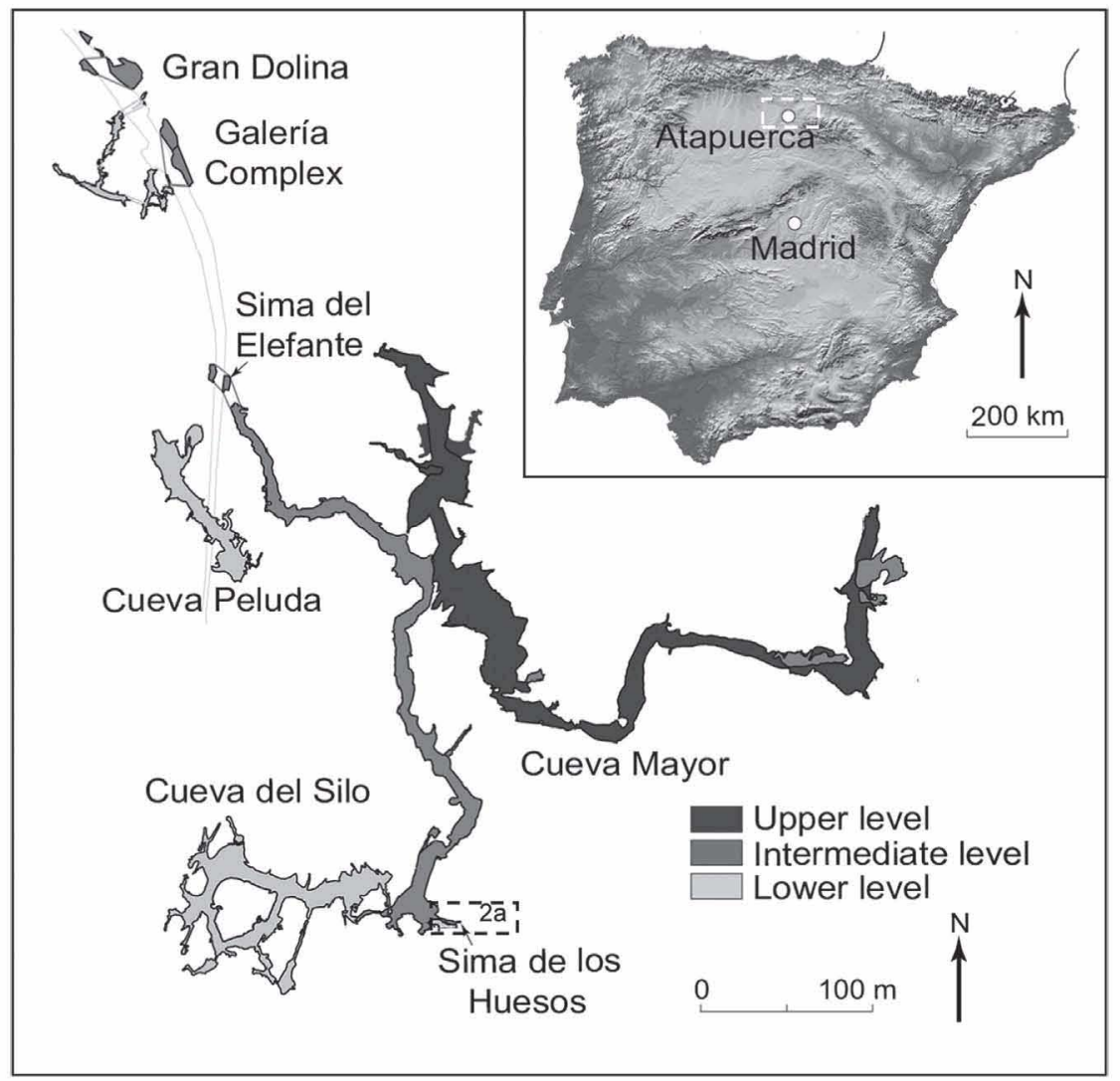

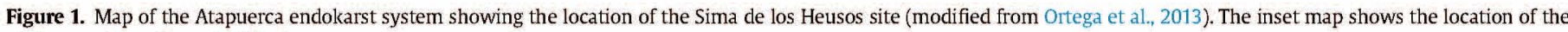
study area in north-central Spain.

inter-population variability in the Middle Pleistocene hominin record (e.g., Arsuaga et al., 1997b,c; Lorenzo et al., 1998; MartinónTorres et al., 2006, 2012). The Sima hominin assemblage is also of importance for understanding the origins of the Neanderthal lineage since the fossils display some Neanderthal traits and have been cited as evidence for a Homo heidelbergensis-Homo neanderthalensis continuum in Europe (e.g., Arsuaga et al., 1993, 1997a,b; Rosas, 2001; Bermúdez de Castro et al., 2004; Hublin, 2009; Martinón-Torres et al,, 2012). Debate continues, however, over the phylogenetic relationships of Early to Middle Pleistocene hominin populations, and the nature and timing of evolutionary divergences in the Eurasian hominin lineage (e.g., Arsuaga et al., 1997b; Endicott et al., 2010; Dennell et al., 2011; Stringer, 2012; Bermúdez de Castro and Martinón-Torres, 2013). Establishing unequivocal age constraint on the Sima fossils is therefore critical for understanding the palaeoanthropological history and palaeoclimatic context of this site and has broader implications for evaluating competing models of Middle Pleistocene human evolution.

Reliable dating of unheated sedimentary material within Middle Pleistocene karstic cave systems remains a challenge for many geochronological techniques. Two approaches that offer good potential for establishing age control in such settings are palaeomagnetic reversal dating and luminescence dating techniques. Palaeomagnetic dating has been extensively applied to the endokarstic infill sequences at Atapuerca (e.g., Parés and PérezGonzález, 1995, 1999; Parés et al., 2000, 2006, 2010, 2013) and has been integral in establishing a Lower Pleistocene age for the Homo antecessor fossils at Sima del Elefante and Gran Dolina (Carbonell et al., 1995; Carbonell, 2008). Luminescence dating techniques, particularly single-grain optically stimulated luminescence (OSL) dating of quartz (e.g., Murray and Roberts, 1997; Duller, 2008), are increasingly being used to date Late Pleistocene archaeological deposits in cave and rock shelter settings (e.g., Bowler et al., 2003; Bouzouggar et al., 2007; Petraglia et al., 2007; Jacobs et al., 2008; Armitage et al., 2011). However, conventional quartz OSL methods are limited in their application to Middle Pleistocene sites because the main signal used for dating (the socalled 'fast component') becomes saturated with respect to radiation dose over longer timescales. Dose saturation effects typically impose a practical upper age limit of $\sim 100-200 \mathrm{ka}$ (thousands of years) for quartz OSL, depending on sample-specific luminescence properties and the specific activities of radionuclides in the sedimentary matrix. Nevertheless, the last decade has seen the emergence of several 'extended-range' luminescence dating techniques that make use of alternative luminescence signals with significantly higher dose saturation limits (e.g., Fattahi and Stokes, 2000; Singarayer et al., 2000; Huot et al., 2006; Wang et al., 2006a,b; Jain et al., 2007; Thomsen et al., 2008).

Two such extended-range luminescence dating techniques offer particularly good potential to circumvent conventional OSL restrictions at Middle Pleistocene sites such as Sima de los Huesos: namely, thermally transferred OSL dating of quartz (TT-OSL; Wang et al., 2006a,b) and post-infrared-infrared stimulated luminescence dating of K-feldspars (pIR-IR; Thomsen et al., 2008; Buylaert et al., 2009). Thermally transferred OSL is the light-sensitive signal observed following initial depletion of the main OSL signal and application of a preheat treatment to induce a transfer of charge into the conventional quartz dating trap (e.g., Duller and Wintle, 
(a)

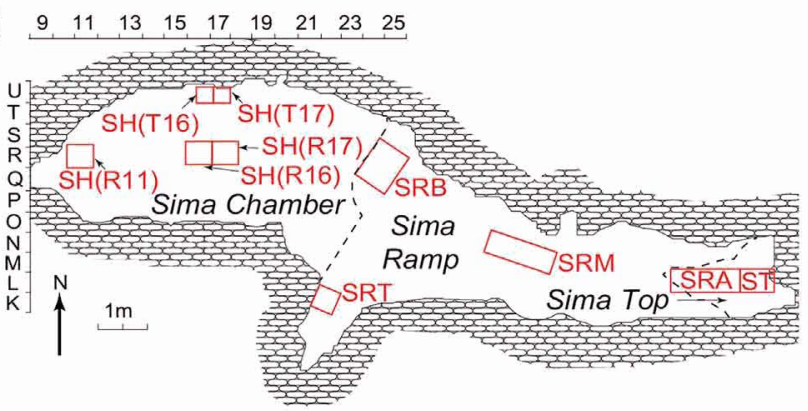

(b)

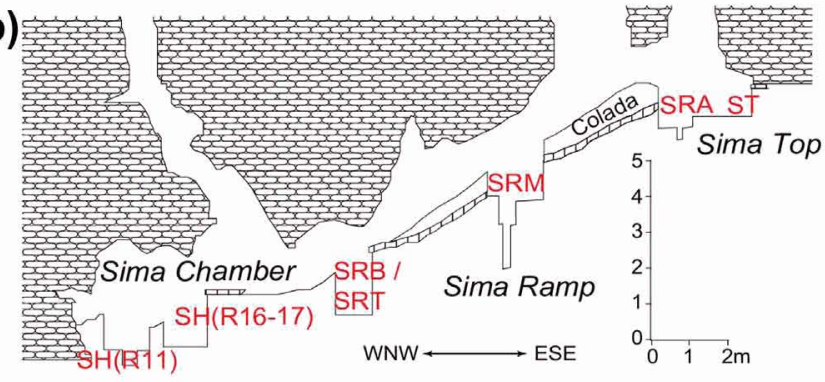

(c)

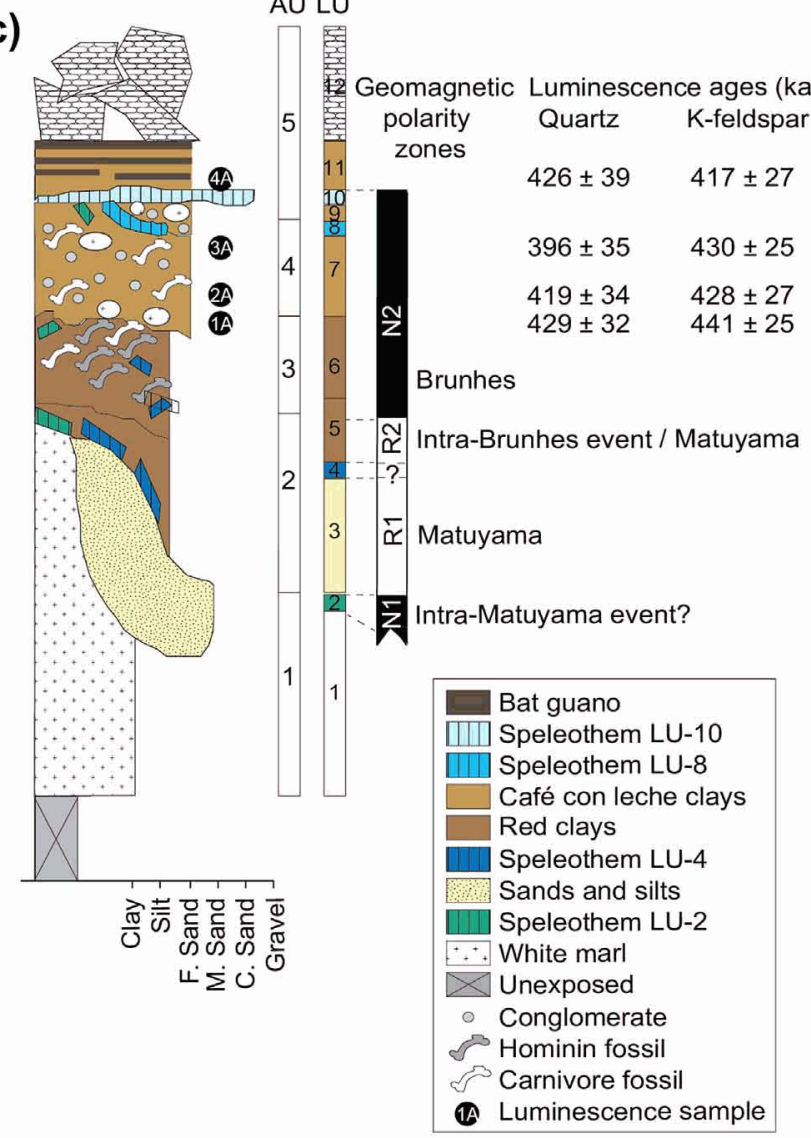

Figure 2. Overview of the Sima de los Huesos site and sampling exposures, (a) Plan view of the site showing the luminescence dating and palaeomagnetic sampling localities. (b) west north-west to east south-east longitudinal transect across the Sima chamber, Sima ramp and Sima top sections. (c) Generalised stratigraphic sequence showing the K-feldspar ( $\mathrm{pIR}-\mathrm{IR}_{225}$ ) and quartz (single-grain TT-OSL) luminescence ages obtained at SRB and SRM. The inferred geomagnetic polarity zones (black = normal; white $=$ reversed) are based on the new results presented in this study and the previously published results of Parés et al. (2000). AU and LU = allostratigraphic units and lithostratigraphic units.
2012). The pIR-IR dating method has been developed out of attempts to circumvent the problem of anomalous fading in feldspars (i.e., unexpected signal loss relative to predicted electron trap lifetimes), which causes apparent age underestimation (Spooner, 1992, 1994; Huntley and Lamothe, 2001). The pIR-IR approach involves measuring an elevated temperature infrared stimulated luminescence (IRSL) signal immediately after performing a lower temperature IRSL bleach (e.g., Thomsen et al., 2008), with the aim of accessing distant electron-hole pairs that have low probabilities of tunnelling recombination during burial. Both TT-OSL and PIR-IR have been used to derive accurate ages over Middle Pleistocene timescales across a range of depositional contexts (e.g., Wang et al., 2006a; Sun et al., 2010; Jacobs et al., 2011; Kang et al., 2011; Thiel et al., 2011; Buylaert et al., 2012; Li and Li, 2012; Lowick et al., 2012; Roberts, 2012; Vasiliniuc et al., 2012; Arnold et al., 2013; Rink et al., 2013). There are also a growing number of reliable TTOSL and pIR-IR dating applications in potentially complex archaeological cave or rock shelter settings (Gliganic et al., 2012a,b; Pickering et al., 2013; Rink et al., 2013; Sun et al., 2013).

Here we present new luminescence dating and palaeomagnetic results for sedimentary infill deposits that are directly related to the hominin fossils at Sima de los Huesos. The main aim of the study is to provide a more reliable, bracketing chronological framework for the hominin assemblage using a multifaceted dating approach. For the luminescence dating analyses, we have opted to use both TTOSL and pIR-IR techniques in tandem. This dual approach provides us with two semi-independent chronological datasets for different mineralogical components of each sample, thereby enabling internal checks on dating consistency and affording added robustness in the final ages. The resultant chronologies are discussed with respect to methodological considerations and other age constraints established at the site. We also examine the broader compatibility of our ages with other well-dated ancestral Neanderthal sites across Europe and with genetic divergence estimates for the Middle Pleistocene hominin record.

\section{Site description and sample details}

Details of the Sima de los Huesos stratigraphy have been published previously in Arsuaga et al. (1997a) and Bischoff et al. (1997, 2003,2007 ). A revision of the sedimentary record will be presented in a forthcoming manuscript (Arsuaga et al., submitted), as part of an accompanying study to the present chronological research. The latest sedimentological interpretations, which focus on a more quantitative analysis of spatio-temporal relationships among different horizons and exposures, enable identification of twelve distinct lithostratigraphic units that can be grouped into five allostratigraphic members, each delimited by erosive contacts. Fig. $2 \mathrm{c}$ summarises the generalised stratigraphic column of the site according to the new classification scheme. In brief, the sedimentary sequence consists of re-deposited basal Miocene marls and well-sorted fluvial sands and silts, overlain unconformably by sterile red clays (lower red clays), red clay-silts containing hominin and carnivore bones (upper red clays) and clay-silt breccias dominated by bear bones and lithic clasts (café con leche unit) (Fig. 2c). Continuous speleothems and broken, isolated fragments of flowstones are found above the basal marls and fluvial sands and silts (LU-2, LU-4), within the upper red clays (LU-2, LU-4) and intercalated with the clay-silt breccia horizons (LU-8). The whole sequence is sealed by an expansive flowstone (Colada or LU-10) and capped by a clay breccia unit containing distinct bat guano horizons.

Excavations have been conducted in three interconnected areas of the site: (i) Sima ramp (SR): a 9-m long linear chamber with a surface inclination of $\sim 32^{\circ}$; (ii) Sima top section (ST): a shorter, $\sim 1.5 \mathrm{~m}$ horizontal exposure found at the top of the ramp and 

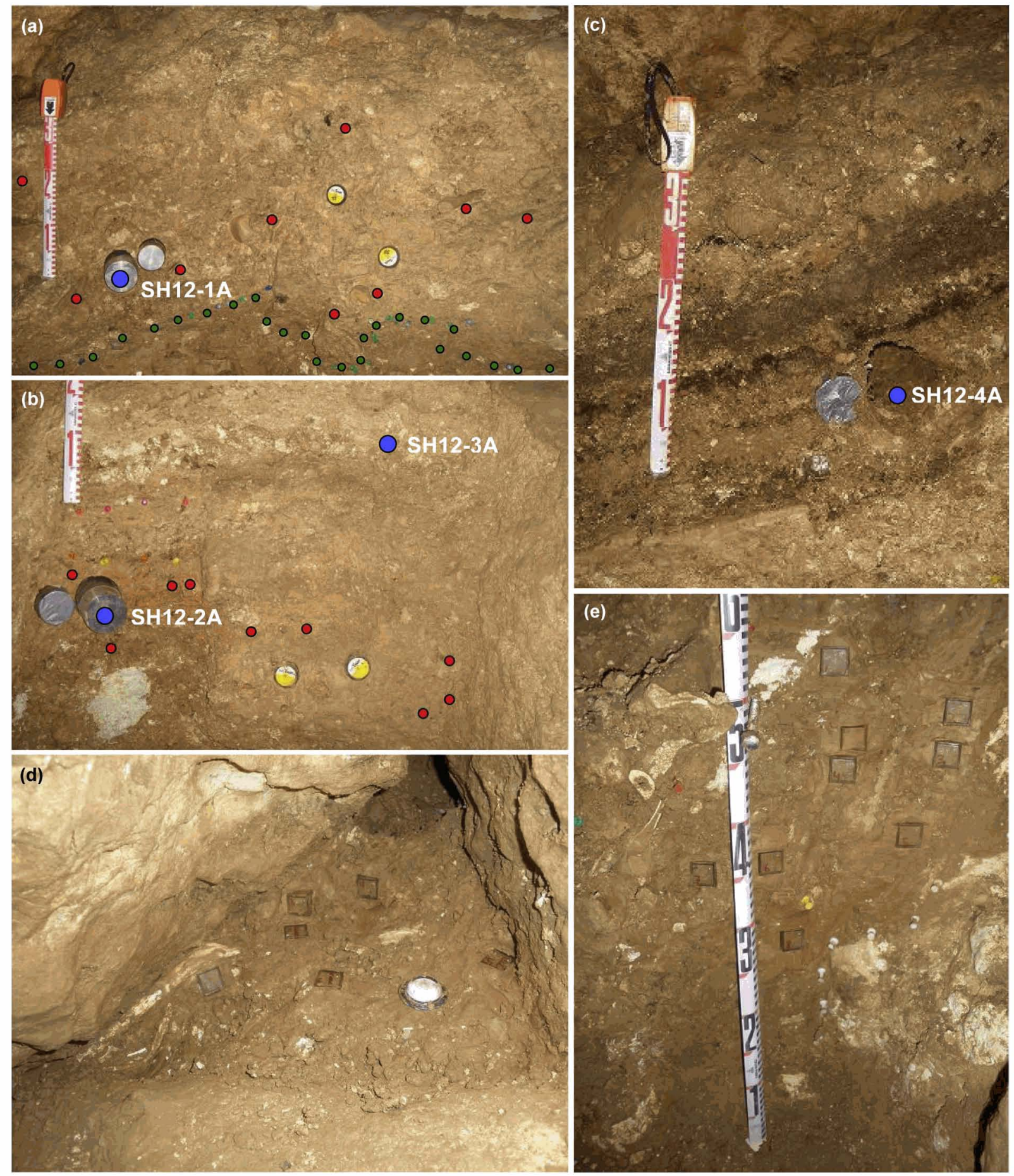

Figure 3. Photographs of the Sima de los Huesos sedimentary sequence, showing locations of the four luminescence dating samples (blue circles) and a selection of the palaeomagnetic samples (transparent cubes). (a) Exposure SRB. Orientation NE (left) to SW (right). The red circles indicate occurrences of carnivore bones, and the stratigraphic boundary between the café con leche and red clay breccia is highlighted by green circles. (b) Exposure SRM showing the luminescence dating sample positions in the café con leche horizon. Orientation NE (left) to SW (right). Distinct clusters of Miocene marl aggregates are visible in the upper layers of the café con leche horizon (at the same depth as SH12-3A) and in the underlying upper red clay breccia (bottom left). (c) Capping clay breccia and guano horizons found overlying the continuous flowstone at SRM. Orientation NW (left) to SE (right). (d) Palaeomagnetism site SH2 (SH(T-17)) next to the northern cave wall. Palaeomagnetic sample positions are shown in the upper red clays, which contain abundant hominin fossils Orientation $\mathrm{N}$ (left) to S (right). (e) Palaeomagnetism site SH3 ( $\mathrm{SH}(\mathrm{R} 16)$ ). Samples were collected from gradational lower to upper red clay horizons. Orientation $\mathrm{E}$ (left) to $\mathrm{W}$ (right). (For interpretation of the references to color in this figure legend, the reader is referred to the web version of this article.)

immediately below the $13 \mathrm{~m}$ vertical entry shaft; and (iii) Sima chamber (SH): a small, $32 \mathrm{~m}^{2}$ terminal chamber at the base of the ramp, from which the vast majority of hominin and faunal remains have been recovered (Fig. $2 a$ and $b$ ). Hominin bones from the same individuals are found dispersed throughout different sectors of the Sima chamber and ramp (e.g., Arsuaga et al., 1997a; Bischoff et al., 2007). The spatial distribution of these bones provides confidence that the chronology established on individual exposures of 
sedimentary infill are directly applicable to the main fossil accumulations found in the $\mathrm{SH}$ chamber.

Four luminescence dating samples were collected from two excavation exposures at Sima de los Huesos (Figs. 2 and 3). One sample was taken from exposure SRB, a $\sim 1.5 \mathrm{~m}$ deep excavation trench located directly adjacent to the main Sima chamber at the base of the inclined Sima ramp. The remaining three samples came from exposure SRM, a similarly sized trench located $\sim 5 \mathrm{~m}$ to the southeast of SRB and midway along the inclined Sima ramp. Luminescence dating samples were collected from cleaned exposures at SRB and SRM using opaque PVC tubes and were wrapped in light-proof bags for transportation and storage. Bulk sediment samples were also collected from the surrounding few centimetres of each sample tube for dose rate determination and water content analysis.

Samples SH12-1A, SH12-2A and SH12-3A were collected from the dark yellowish brown café con leche clay breccia horizon, which contains abundant bear bones at SRB and SRM. Isolated hominin bones are also present in the café con leche deposits at SRB but these are thought to have been reworked at the time of deposition from the underlying hominin-bearing red clay breccia (upper red clays). Samples SH12-1A to $\mathrm{SH} 12-3 \mathrm{~A}$ provide minimum age estimates for the main archaeological horizon found below the café con leche horizon. Luminescence dating samples were not collected directly from the fossiliferous red clays because these units contain relatively low yields of suitably sized silicate minerals and are potentially derived from material that infiltrated slowly through fissures in the bedrock, meaning that the grains may not have been exposed to external daylight immediately prior to deposition. Sample SH12-1A was collected from café con leche deposits, found $33 \mathrm{~cm}$ below the $\sim 5 \mathrm{~cm}$-thick capping flowstone (Colada) at SRB and $13 \mathrm{~cm}$ above the contact with the underlying hominin-bearing red clay breccia. Sample SH12-2A was taken from the lower café con leche deposits at SRM, $43 \mathrm{~cm}$ below the $\sim 10 \mathrm{~cm}$-thick capping flowstone and $5 \mathrm{~cm}$ above the underlying fossiliferous red clay deposits. Sample SH12-3A was collected $40 \mathrm{~cm}$ to the right and $30 \mathrm{~cm}$ above SH12-2A, along the western face of SRM and $15 \mathrm{~cm}$ below the capping flowstone. This sample was taken from the upper part of the café con leche mud breccia, which contains a distinct horizon of greenish white, carbonate-rich, allochthonous Miocene marl pods (Bischoff et al., 1997) (Fig. 3b). Sample SH12-4A was collected $106 \mathrm{~cm}$ to the left of sample SH12-2 from a $40 \mathrm{~cm}-$ thick layer of dark yellowish-brown clay overlying the capping flowstone along the northern wall of SRM. This unit is interbedded with several $<5 \mathrm{~cm}$-thick, dark brownish-black bat guano horizons and contains modern rodent fossils (Cuenca-Bescós et al., 1997). This unit shares similar sedimentological properties (colour, texture, structure) to the café con leche deposits but is devoid of bear bones. Sample SH12-4A was taken from the base of this capping clay breccia, $5 \mathrm{~cm}$ above the contact with the flowstone and $5 \mathrm{~cm}$ below a prominent guano horizon. Uranium series and ${ }^{14} \mathrm{C}$ ages obtained on the immediately underlying flowstone (Bischoff et al., 1997) indicate that the SH12-4 sediments were deposited sometime after $18-68 \mathrm{ka}$.

The poorly sorted, massive nature of the café con leche accumulations, together with the presence of well-rounded pebbles and conglomerate fragments sourced from nearby surficial Miocene deposits, indicates emplacement of these allochthonous units by a (series of) high-energy, debris flow event(s) originating from the cave exterior (Arsuaga et al., 1997a). Importantly, the café con leche deposits display some shared mineralogical and sedimentological properties with the sub-aerial surface deposits adorning the surrounding hillslopes (e.g., Bischoff et al., 1997; Arsuaga et al., submitted), revealing a likely aeolian origin for the silt-sized silicate grains being dated in this study before they were washed into the cave. From a luminescence dating perspective, high-energy transportation within the cave system is advantageous because it significantly reduces the chances that the café con leche sediments suffered protracted residency times or punctuated retransportation episodes within higher parts of the endokarst complex prior to their final deposition. It seems improbable that there would have been sufficient daylight exposure to reset (bleach) the previously accumulated luminescence signals of all sediment grains during these high-energy debris flow events. However, the aeolian source sediments from which these mudflow deposits were derived are likely to have received prolonged and direct sunlight exposure prior to entrainment and transportation into the cave. Providing that the source sediments had accumulated relatively recently before being washed into the cave (i.e., compared with the expected Middle Pleistocene ages of the Sima archaeological deposits), it seems reasonable to assume that the café con leche sediments could have been fully bleached at deposition, or else retained only very minor residual luminescence signals. Indeed, Berger et al. (2008) demonstrated that the presentday surface sediments surrounding the Atapuerca endokarst system have very low residual IRSL signals of $0.8-19.3 \mathrm{~Gy}$ (average multi-grain aliquot equivalent dose $\left(D_{e}\right)=3.2 \pm 1.3 \mathrm{~Gy} ; n=6$ ). If similar surface sediments were washed into the caves in the past, they would have only yielded residual ages of $0.3-6.0 \mathrm{ka}$, which would be effectively inconsequential over the Middle Pleistocene burial timescales considered here. To directly test the assumption that the natural pIR-IR and TT-OSL signals of the café con leche Sima samples could have been adequately bleached prior to their arrival in the endokarst system, we collected a modern sediment sample from the hillslope located directly outside the entrance to Cueva Mayor (El Portalon). While the geological provenance of the quartz and feldspar grains in this modern sample may not necessarily match that of the prehistoric Sima deposits, the sample does represent a useful analogue for the geomorphic and transportation history of the clay breccia sediments being dated in this study.

A total of 105 oriented palaeomagnetic samples were collected from sedimentary clay horizons and flowstones at eight localities within the main Sima chamber and along the inclined Sima ramp (Table 1, Figs. 2 and 3). Thirty-three sediment samples were collected from the hominin-bearing upper red clay horizon at exposures $\mathrm{SH}(\mathrm{T} 17)$ and $\mathrm{SH}(\mathrm{R} 17)$, located along the northern and southern walls of the main Sima chamber, respectively, and at exposure SRA, a 1-m trench located at the head of the Sima ramp. The underlying sterile lower red clays were sampled at an adjacent exposure along the northern wall of the main chamber (SH(T16), and an additional 18 samples were collected from gradational zones spanning the base of the upper red clays and top of the lower red clays in excavation squares SH(R11) and SH(R16). The overlying café con leche clay breccia deposits were sampled at excavation trench SRT (Sima ramp Tenerife or excavation square SH(K22)), which represents a laterally correlative exposure of SRB along the southwest margin of the inclined Sima ramp. Twenty-four samples were collected from two flowstones preserved at exposure SRA: speleothem LU-10, which caps the entire sedimentary sequence, and speleothem LU-8, found overlying in situ café con leche deposits. Eleven samples were also collected from a large flowstone at the adjacent exposure of ST, which comprises three generations of speleothem denoted ST-a, ST-b and ST-c. Speleothems ST-b and ST-c correspond to the lower and upper parts of speleothem SRA-3 reported in Bischoff et al. (2003, 2007). In these earlier studies, speleothem SRA-3 was interpreted as being correlated to flowstone LU-8 at SRA, which clearly overlies the fossiliferous layers. However, with subsequent excavations and more detailed stratigraphic and petrographic analysis, it is now clear that both speleothem ST-a and the lower part of SRA-3 (i.e., ST-b) correspond to LU-2 at 
Table 1

Palaeomagnetic data summary for the Sima de los Huesos samples.

\begin{tabular}{|c|c|c|c|c|c|c|c|c|}
\hline $\begin{array}{l}\text { Palaeomagnetism } \\
\text { reference }\end{array}$ & Site reference & Sedimentary unit & $\begin{array}{l}\text { Sample depth } \\
\text { (m) }\end{array}$ & $\begin{array}{c}\text { Dec } \\
\text { (degrees) }\end{array}$ & $\begin{array}{c}\text { Inc } \\
\text { (degrees) }\end{array}$ & $\begin{array}{c}\alpha 95 \\
\text { (degrees) }\end{array}$ & K & $n / N$ \\
\hline SH1 & $\mathrm{SH}(\mathrm{R} 11)$ & Lower/upper red clays & 0.20 & 342.2 & 50.8 & 12.4 & 30 & $6 / 8$ \\
\hline $\mathrm{SH} 2$ & $\mathrm{SH}(\mathrm{T}-17)$ & Upper red clays & 0.30 & 355.4 & 57.7 & 17.3 & 20 & $5 / 7$ \\
\hline SH3 & SH(R16) & Lower/upper red clays & $0.50-0.80$ & 3.6 & 58.7 & 13.6 & 15 & $9 / 10$ \\
\hline $\mathrm{SH} 4$ & SH(R17) & Upper red clays & 1.10 & 8.8 & 63.9 & 10.4 & 42 & $6 / 8$ \\
\hline SH5 & SH(T16) & Lower red clays & 0.60 & 5.5 & 53.1 & 8.4 & 65 & $6 / 10$ \\
\hline SH6 & SRT(K22) & Café con leche clays & 0.20 & 357.3 & 61.7 & 9.1 & 45 & $7 / 9$ \\
\hline SRAI & SRA & Upper red clays & 0.30 & 359.0 & 59.8 & 5.2 & 52 & $17 / 18$ \\
\hline SRA1 & SRA & LU-10 and LU-8 flowstones & $0.05-0.50$ & 11.8 & 61.6 & 3.9 & 62 & $23 / 24$ \\
\hline SRA2 & ST & $\begin{array}{l}\text { LU-2 (including ST- } a, b \text { ) and } \\
\text { LU-8 (ST-c) flowstones }\end{array}$ & $0.05-0.20$ & 351.9 & 63.1 & 8.5 & 38 & $9 / 11$ \\
\hline
\end{tabular}

Dec: Declination, Inc: Inclination, $\alpha_{95}$ : Radius of $95 \%$ confidence; $\mathrm{k}$ : fisher parameter, $n / N$ : number of used/measured specimens.

exposure SRA, and therefore underlie the red clay horizons and the sand and silt horizons in the revised lithostratigraphic scheme (Fig. 2). Only the upper portion of SRA-3 (i.e., ST-c) can be correlated with LU-8 at exposure SRA, as detailed in the new stratigraphic scheme of Arsuaga et al. (submitted). In addition to collecting the main samples for determining magnetic polarity, we also took ancillary sediment samples at each sampling locality for rockmagnetism measurements.

Clay horizons were sampled for palaeomagnetic dating using standard $8 \mathrm{~cm}^{3}$ cubic boxes. The sedimentary facies at SH, SRT and SRA were all soft enough to allow the sampling boxes to be gently pushed into the exposures and extracted using a ceramic knife after recording the azimuth and dip. Flowstone samples were collected at SRA and ST using a portable electric drill equipped with a 1-inch non-magnetic drill bit. Following collection and transportation, all palaeomagnetic samples were stored in a laboratory cooler to prevent water loss and other post-sampling alterations. Core samples were sliced into standard $2.1 \mathrm{~cm}$-long specimens prior to measurement.

\section{Experimental approaches}

\section{Luminescence dating procedures}

In the laboratory, quartz and K-feldspar grains of 90-125 $\mu \mathrm{m}$ and $125-180 \mu \mathrm{m}$ diameter were extracted from the un-illuminated centres of the PVC tube samples under safe (dim red) light conditions and prepared for burial dose estimation using standard procedures (Aitken, 1998). Separated fractions of quartz and Kfeldspar grains were etched with $48 \%$ hydrofluoric (HF) acid for $40 \mathrm{~min}$ and $10 \% \mathrm{HF}$ acid for $10 \mathrm{~min}$, respectively, to remove their alpha-irradiated external layers. Thermally transferred OSL and pIR-IR measurements were made using the same experimental apparatus described by Arnold et al. (2013). Ultraviolet OSL emissions from quartz were detected using an EMI 9235QA photomultiplier tube fitted with 7.5 mm-thick Hoya U-340 filters. Potassium feldspar IRSL emissions were detected in the blue region of the spectrum using a combination of 3 mm-thick BG39 and 4 mm-thick Corning 7-59 filters. Samples were irradiated with a mounted ${ }^{90} \mathrm{Sr} /{ }^{90} \mathrm{Y}$ beta-source that had been calibrated to administer known doses to multi-grain aliquots and single-grain discs. For single-grain measurements, spatial variations in beta dose rates across the disc plane were taken into account by undertaking holespecific calibrations using gamma-irradiated quartz.

Laboratory bleaching studies have revealed that natural $\mathrm{K}$ feldspar pIR-IR signals are reset relatively rapidly by simulated daylight, albeit an order of magnitude slower than for conventional quartz OSL signals, i.e., initial signal intensities are depleted by over $90 \%$ within several tens of seconds to several tens of minutes using a SOL2 solar simulator (depending on choice of preheat and pIR-IR stimulation temperature, e.g., Thomsen et al., 2008; Buylaert et al., 2012). In the present study, we have performed pIR-IR stimulations at $225{ }^{\circ} \mathrm{C}$ following a preheat of $250{ }^{\circ} \mathrm{C}$ for $60 \mathrm{~s}$ (i.e., a pIR-IR 225 procedure). Modern samples from a range of well-bleached aeolian deposits typically display relatively low residual doses on the order of $<5$ Gy for pIR-IR 225 procedures (e.g., Buylaert et al., 2011), and up

Table 2

Single-aliquot regenerative-dose (SAR) procedures used for $D_{e}$ determination.

\begin{tabular}{|c|c|c|c|c|c|}
\hline \multicolumn{3}{|c|}{ a: Multi-grain aliquot pIR-IR SAR procedure } & \multicolumn{3}{|c|}{ b: Single-grain TT-OSL SAR procedure } \\
\hline Step & Treatment & Signal & Step & Treatment & Signal \\
\hline 1 & Dose (natural or laboratory) & & 1 & Dose (natural or laboratory) & \\
\hline 2 & Preheat $1\left(250^{\circ} \mathrm{C}\right.$ for $\left.60 \mathrm{~s}\right)$ & & 2 & Preheat $1\left(260^{\circ} \mathrm{C}\right.$ for $\left.10 \mathrm{~s}\right)$ & \\
\hline 3 & IR stimulation $\left(50^{\circ} \mathrm{C}\right.$ for $\left.200 \mathrm{~s}\right)$ & & 3 & Single-grain OSL stimulation $\left(125^{\circ} \mathrm{C}\right.$ for $3 \mathrm{~s}$ ) & \\
\hline 4 & pIR-IR stimulation $\left(225^{\circ} \mathrm{C}\right.$ for $200 \mathrm{~s}$ ) & $L_{n}$ or $L_{x}$ & 4 & Preheat $2\left(260^{\circ} \mathrm{C}\right.$ for $\left.10 \mathrm{~s}\right)$ & \\
\hline 5 & Test dose (100 Gy) & & 5 & Single-grain TT-OSL stimulation ( $125^{\circ} \mathrm{C}$ for $3 \mathrm{~s}$ ) & $L_{n}$ or $L_{x}$ \\
\hline 6 & Preheat $2\left(250^{\circ} \mathrm{C}\right.$ for $\left.60 \mathrm{~s}\right)$ & & 6 & OSL stimulation $\left(280^{\circ} \mathrm{C}\right.$ for $\left.400 \mathrm{~s}\right)$ & \\
\hline 7 & IR stimulation $\left(50^{\circ} \mathrm{C}\right.$ for $\left.200 \mathrm{~s}\right)$ & & 7 & Test dose (200 Gy) & \\
\hline 8 & pIR-IR stimulation $\left(225^{\circ} \mathrm{C}\right.$ for $\left.200 \mathrm{~s}\right)$ & $T_{\mathrm{n}}$ or $T_{\mathrm{x}}$ & 8 & Preheat $3\left(220^{\circ} \mathrm{C}\right.$ for $\left.10 \mathrm{~s}\right)$ & \\
\hline \multirow[t]{5}{*}{9} & Repeat measurement cycle for different sized regenerative doses & & 9 & Single-grain OSL stimulation $\left(125^{\circ} \mathrm{C}\right.$ for $\left.3 \mathrm{~s}\right)$ & \\
\hline & & & 10 & Preheat $4\left(260^{\circ} \mathrm{C}\right.$ for $\left.10 \mathrm{~s}\right)$ & \\
\hline & & & 11 & Single-grain TT-OSL stimulation $\left(125^{\circ} \mathrm{C}\right.$ for $3 \mathrm{~s}$ ) & $T_{\mathrm{n}}$ or $T_{x}$ \\
\hline & & & 12 & OSL stimulation $\left(290^{\circ} \mathrm{C}\right.$ for $\left.400 \mathrm{~s}\right)$ & \\
\hline & & & 13 & $\begin{array}{l}\text { Repeat measurement cycle for different } \\
\text { sized regenerative doses }\end{array}$ & \\
\hline
\end{tabular}

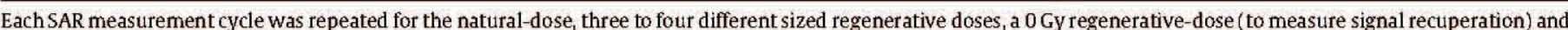

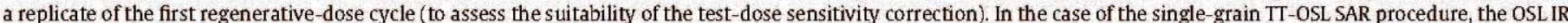

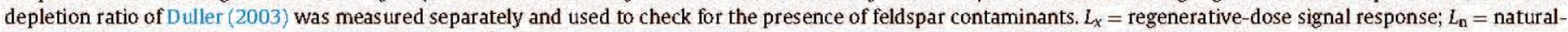
dose signal response; $T_{x}=$ test-dose signal response for a laboratory dose cycle; $T_{n}=$ test-dose signal response for the natural-dose cycle. 
Table 3

Environmental dose rate data for the Sima de los Huesos luminescence dating samples.

\begin{tabular}{|c|c|c|c|c|c|c|c|c|c|c|c|c|c|c|c|c|}
\hline \multirow[t]{2}{*}{ Sample } & \multirow{2}{*}{$\begin{array}{c}\text { Sample } \\
\text { depth } \\
\text { (m) }\end{array}$} & \multirow{2}{*}{$\begin{array}{l}\text { Grain } \\
\text { size } \\
(\mu \mathrm{m})\end{array}$} & \multirow{2}{*}{$\begin{array}{c}\text { Water } \\
\text { content } \\
(\%)^{\mathrm{a}}\end{array}$} & \multicolumn{6}{|c|}{ Radionuclide specific activities $(\mathrm{Bq} / \mathrm{kg})^{\mathrm{b}, \mathrm{d}}$} & \multicolumn{5}{|c|}{ 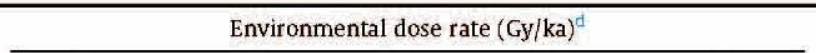 } & \multirow{2}{*}{$\begin{array}{l}\text { Total dose } \\
\text { rate } \\
(\text { quartz) }\end{array}$} & \multirow{2}{*}{$\begin{array}{c}\text { Total dose } \\
\quad \text { rate } \\
\text { (K-feldspar) }^{\text {d, th }}\end{array}$} \\
\hline & & & & ${ }^{238} \mathrm{U}$ & ${ }^{226} \mathrm{Ra}$ & ${ }^{210} \mathrm{~Pb}$ & ${ }^{228} \mathrm{Ra}$ & ${ }^{228} \mathrm{Th}$ & ${ }^{40} \mathrm{~K}$ & $\begin{array}{c}\text { Beta dose } \\
\text { rate }^{c}\end{array}$ & $\begin{array}{c}\text { Gamma dose } \\
\text { rate }^{c}\end{array}$ & $\begin{array}{c}\text { Cosmic dose } \\
\text { rate }^{e}\end{array}$ & $\begin{array}{l}\text { Internal dose } \\
\text { rate (quartz) }\end{array}$ & $\begin{array}{c}\text { Internal dose } \\
\text { rate (K-feldspar) }\end{array}$ & & \\
\hline \multicolumn{17}{|c|}{ Sima ramp middle (SRM) } \\
\hline SH12-4A & 0.35 & $90-125$ & $28 \pm 6$ & $44.0 \pm 6.8$ & $31.6 \pm 3.8$ & $31.1 \pm 2.6$ & $38.9 \pm 3.3$ & $39.9 \pm 2.8$ & $406.0 \pm 13.9$ & $1.14 \pm 0.07$ & $0.63 \pm 0.03$ & $0.01 \pm 0.001$ & $0.03 \pm 0.01$ & $0.49 \pm 0.04$ & $1.80 \pm 0.13$ & $2.26 \pm 0.14$ \\
\hline SH12-3A & 0.53 & $90-125$ & $22 \pm 4$ & $36.0 \pm 4.8$ & $38.6 \pm 2.7$ & $40.1 \pm 0.8$ & $36.1 \pm 3.0$ & $35.6 \pm 2.6$ & $367.3 \pm 12.5$ & $1.11 \pm 0.06$ & $0.66 \pm 0.03$ & $0.01 \pm 0.001$ & $0.03 \pm 0.01$ & $0.49 \pm 0.04$ & $1.80 \pm 0.11$ & $2.26 \pm 0.12$ \\
\hline SH12-2A & 0.83 & $90-125$ & $26 \pm 5$ & $32.5 \pm 4.4$ & $30.2 \pm 2.1$ & $30.0 \pm 0.5$ & $37.8 \pm 3.2$ & $36.8 \pm 2.7$ & $376.9 \pm 12.8$ & $1.08 \pm 0.06$ & $0.62 \pm 0.03$ & $0.01 \pm 0.001$ & $0.03 \pm 0.01$ & $0.49 \pm 0.04$ & $1.74 \pm 0.12$ & $2.20 \pm 0.12$ \\
\hline \multicolumn{17}{|c|}{ Sima ramp bottom (SRB) } \\
\hline SH12-1A & 0.33 & $90-125$ & $20 \pm 4$ & $30.6 \pm 4.9$ & $27.4 \pm 2.0$ & $27.5 \pm 2.3$ & $26.3 \pm 2.2$ & $27.0 \pm 2.0$ & $277.4 \pm 9.6$ & $0.83 \pm 0.04$ & $0.77 \pm 0.03$ & $0.01 \pm 0.001$ & $0.03 \pm 0.01$ & $0.49 \pm 0.04$ & $1.63 \pm 0.10$ & $2.09 \pm 0.10$ \\
\hline
\end{tabular}

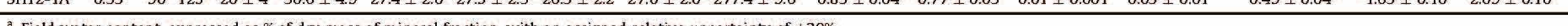

a Field water content, expressed as \% of $\mathrm{dry}$ mass of mineral fraction, with an assigned relative uncertainty of $\pm 20 \%$

${ }^{b}$ Measurements made on dried and powdered samples by high-resolution gamma-ray spectrometry.

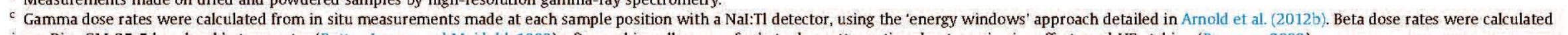
using a Risø GM-25-5 low-level beta counter (Bøtter-Jensen and Mejdahl, 1988), after making allowance for beta dose attenuation due to grain size effects and HF etching (Brennan, 2003).

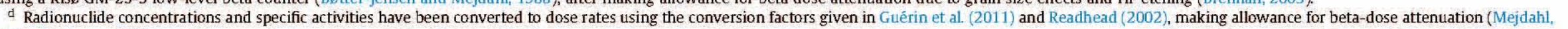
1979; Brennan, 2003).

e Cosmic-ray dose rates were calculated using the approach of Prescott and Hutton (1994) and assigned a relative uncertainty of $\pm 10 \%$.

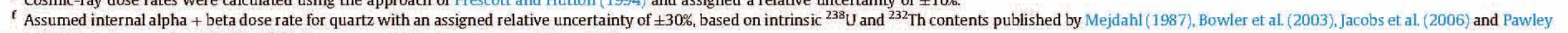
et al. (2008), and an $a$-value of $0.04 \pm 0.01$ (Rees-Jones, 1995; Rees-Jones and Tite, 1997).

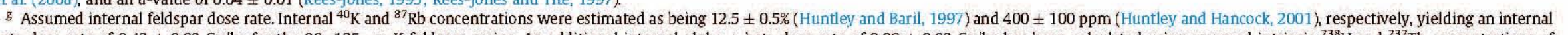

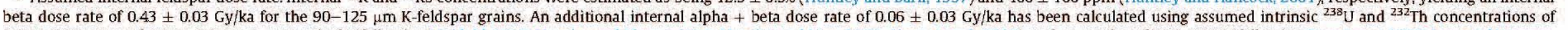

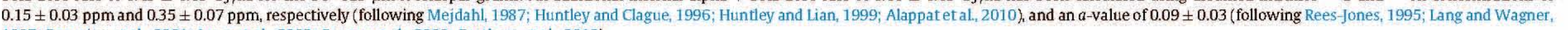
1997; Banerjee et al., 2001; Lang et al., 2003; Berger et al., 2008; Feathers et al., 2012).

${ }^{b}$ Mean \pm total uncertainty ( $68 \%$ confidence interval), calculated as the quadratic sum of the random and systematic uncertainties. 
to several tens of Gy for pIR-IR stimulations performed at $290{ }^{\circ} \mathrm{C}$ following a preheat of $320^{\circ} \mathrm{C}$ for $60 \mathrm{~s}$ (i.e., a pIR-IR 290 procedure) (Buylaert et al., 2012). Together, these results suggest that unbleachable/thermally transferred residual pIR-IR signals are unlikely to yield noticeable age inaccuracies for most Middle Pleistocene age samples and that the use of multi-grain aliquot dating procedures is nominally suitable in the present depositional context.

Unlike pIR-IR signals, natural quartz TT-OSL signals have been shown to bleach very slowly (Duller and Wintle, 2012), taking on the order of several weeks to be depleted by $>80-90 \%$ in solar simulator experiments (e.g., Tsukamoto et al., 2008; Porat et al., 2009) and several months to be significantly depleted by natural daylight (e.g., Jacobs et al., 2011; Arnold et al., 2013). Suitably low $D_{e}$ residuals of a few tens of Gy have, however, been recorded in wellbleached modern samples (Duller and Wintle, 2012). The slowly bleaching nature of the TT-OSL signal dictates that there is greater potential for insufficient signal resetting (and concomitant age overestimation) in most depositional settings when using multigrain aliquot TT-OSL approaches. For this reason, we have cautiously chosen to use a single-grain TT-OSL dating procedure in the present study, which ensures that any partially bleached grain populations can be identified more reliably and treated with an appropriate statistical model in the final age calculation. The potential for applying single-grain TT-OSL dating procedures to Middle Pleistocene deposits from the Sierra de Atapuerca is greatly enhanced by the inherently bright OSL signal intensities of quartz from the upper Duero Basin (Arnold et al., 2012a), and this approach has been recently used to reliably date nearby Middle Pleistocene fluvial terrace deposits in the Pico valley (Arnold et al., 2013). Single-grain TT-OSL ages obtained in the study of Arnold et al. (2013) were in good agreement with an associated singlegrain OSL 'supergrain' age, as well as with a series of quartz ESR ages (Moreno et al., 2012), TL ages and palaeomagnetic polarity results (Benito-Calvo et al., 2008) for bracketing fluvial terraces.

Quartz and K-feldspar $D_{\mathrm{e}}$ values were determined using pIR-IR and TT-OSL versions of the single-aliquot regenerative-dose (SAR) procedure (Murray and Wintle, 2000) shown in Table 2. In these SAR protocols, sensitivity changes are corrected for by measuring the TT-OSL/pIR-IR signal response to a test-dose $\left(T_{x}\right)$ given after the natural $\left(L_{n}\right)$ or regenerated $\left(L_{x}\right)$ TT-OSL/pIR-IR signals have been measured. Sensitivity-corrected luminescence responses are then determined by dividing the natural and regenerated TT-OSL/pIR-IR intensities by their respective test-dose signal intensities $\left(L_{\mathrm{n}} / T_{\mathrm{n}}\right.$ and $L_{x} / T_{x}$, respectively). Further details of the SAR procedures, including dose-recovery validation tests and quality assurance criteria used to eliminate unreliable grains and aliquots, are provided in the Supplementary Online Material (SOM).

Environmental dose rates have been calculated using a combination of field gamma-ray spectrometry and low-level beta counting (Table 3). High-resolution gamma spectrometry was additionally performed on each of the luminescence dating samples to assess the present-day state of secular (dis)equilibrium in the ${ }^{238} \mathrm{U}$ and ${ }^{232} \mathrm{Th}$ decay series. Full details of the procedures used to calculate the environmental dose rates for the quartz and $\mathrm{K}$ feldspar fractions are provided in the SOM.

\section{Palaeomagnetic dating procedures}

Palaeomagnetic analyses were carried out at the Palaeomagnetism Laboratory of the Centro Nacional de Investigación sobre la Evolución Humana (CENIEH), Burgos, Spain. Measurements of the Natural Remanent Magnetisation, and its decay during demagnetisation, were carried out on a $2 \mathrm{G}$ Enterprises $755-4 \mathrm{~K}$ Superconducting Rock Magnetometer, housed in a low-magnetic
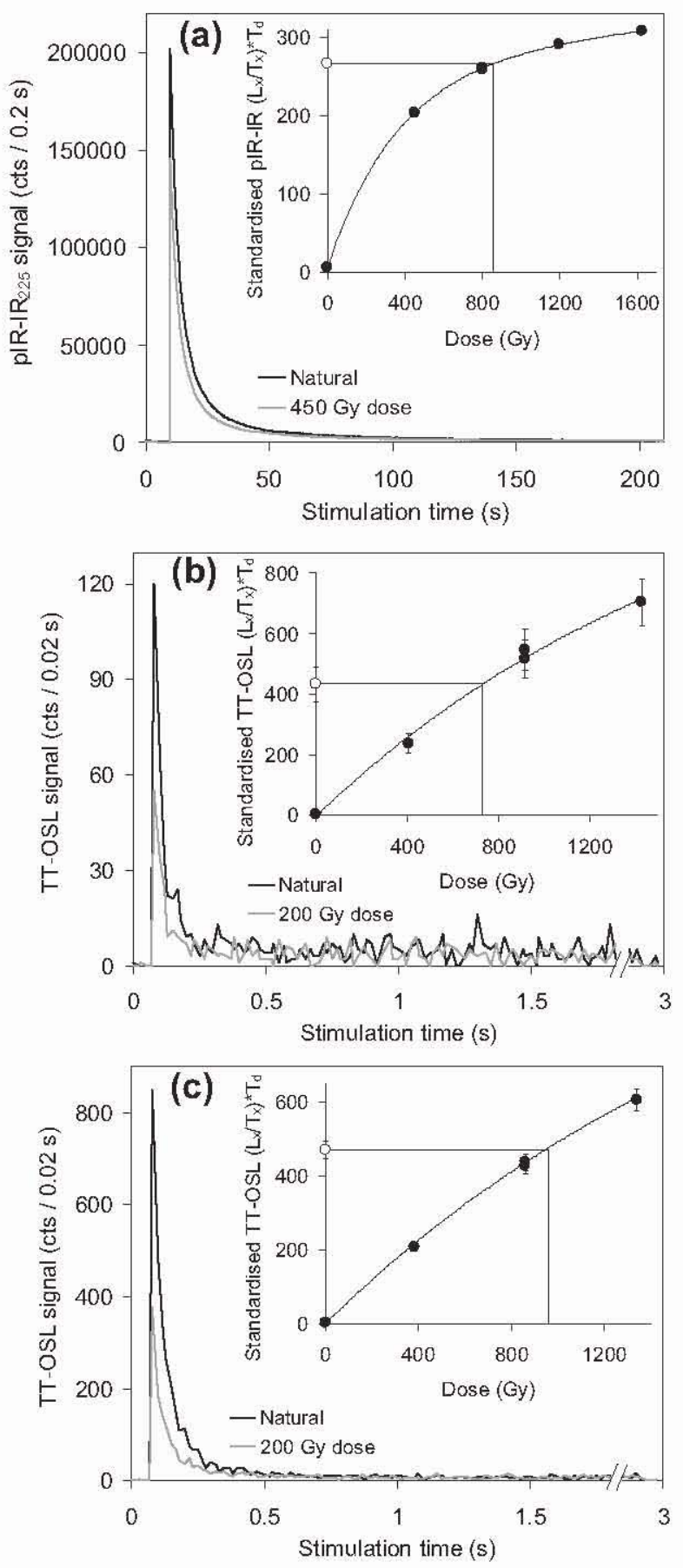

Figure 4. Representative pIR-IR 225 and TT-OSL decay curves for the SH12 luminescence dating samples. The inset plots show corresponding sensitivity-corrected doseresponse curve for each aliquot/grain. The open circles on the inset plot $y$-axes denote the sensitivity-corrected natural pIR-IR 225 or TT-OSL signals, and the sensitivitycorrected regenerated pIR-IR 225 and TT-OSL signals are shown as filled circles. (a) $\sim 350$-grain K-feldspar aliquot of sample SH12-1A. (b) Quartz grain from sample SH12$3 \mathrm{~A}$ with an average TT-OSL signal (i.e., $T_{n}=100-500$ counts/0.17 s). (c) Quartz grain from sample SH12-1A with a relatively bright TT-OSL signal $\left(T_{n}>1000\right.$ counts $\left./ 0.17 \mathrm{~s}\right)$. The 200 Gy decay curves shown in (b-c) represent test-dose TT-OSL responses.

environment and created using a set of large Helmholtz coils. The magnetometer has a built-in degausser for alternating field (AF) demagnetisation up to $170 \mathrm{mT}$. Thermal demagnetisation apparatus includes a TD-48SC oven (ASC Scientific). Hysteresis and isothermal remanent magnetisation (IRM) curves were obtained with a Princeton Measurements Corporation Vibrating Sample 
Table 4

Summary statistics for the pIR-IR $D_{\mathrm{e}}$ measurements, age model results and final ages of the Sima de los Huesos samples.

\begin{tabular}{|c|c|c|c|c|c|c|c|c|c|c|c|c|c|c|c|}
\hline \multirow[t]{2}{*}{ Sample } & \multirow{2}{*}{$\begin{array}{l}\text { Sample } \\
\text { depth } \\
\text { (m) }\end{array}$} & \multirow{2}{*}{$\begin{array}{l}\text { Grain } \\
\text { size } \\
(\mu \mathrm{m})\end{array}$} & \multirow{2}{*}{$\begin{array}{c}\text { Total } \\
\text { dose rate } \\
\text { (Gy/ka) }\end{array}$} & \multirow{2}{*}{$\begin{array}{l}\mathrm{D}_{\mathrm{e}} \text { type and } \\
\text { resolution }^{\mathrm{a}}\end{array}$} & \multirow{2}{*}{$\begin{array}{c}\text { Accepted/ } \\
\text { measured } \\
D_{\mathrm{e}} \text { values }\end{array}$} & \multirow{2}{*}{$\begin{array}{c}\text { Fading rate } \\
\mathrm{g}_{2 \text { days }} \\
\text { (\%/decade) }\end{array}$} & \multirow{2}{*}{$\begin{array}{l}\text { Weighted } \\
\text { skewness }^{c}\end{array}$} & \multirow{2}{*}{$\begin{array}{c}\text { Critical } \\
\text { skewness } \\
(95 \% \text { C.I. })^{d}\end{array}$} & \multicolumn{3}{|c|}{ CAM results $^{e}$} & \multicolumn{4}{|c|}{ MAM results ${ }^{e}$} \\
\hline & & & & & & & & & $\begin{array}{l}\text { Overdispersion } \\
\text { (\%) }\end{array}$ & $\begin{array}{l}\mathrm{CAM} D_{\mathrm{e}} \\
(\mathrm{Gy})^{f}\end{array}$ & $\begin{array}{l}\text { CAM age } \\
(\mathrm{ka})^{\mathrm{r}, \mathrm{g}, \mathrm{h}}\end{array}$ & $\begin{array}{l}\text { MAM-3 } \\
D_{\mathrm{e}}(\mathrm{Gy})^{\mathrm{f}}\end{array}$ & $\begin{array}{l}\text { MAM-3 } \\
\text { age }(\mathbf{k a})^{f, g}\end{array}$ & $\begin{array}{l}\text { MAM-4 } \\
D_{\mathrm{e}}(\mathrm{G} y)^{f}\end{array}$ & $\begin{array}{l}\text { MAM-4 } \\
\text { age }(\mathrm{ka})^{i, g}\end{array}$ \\
\hline \multicolumn{16}{|c|}{ Modern analogue sample $e^{i}$} \\
\hline SH12-5A & 0.05 & $90-125$ & - & MG (350 grains) & $6 / 6$ & - & -0.24 & \pm 2.00 & $24 \pm 7$ & $7.3 \pm 0.8$ & - & $4.9 \pm 0.1$ & - & $4.9 \pm 0.1$ & - \\
\hline \multicolumn{16}{|c|}{ Sima ramp middle (SRM) } \\
\hline SH12-4A & 0.35 & $90-125$ & $2.26 \pm 0.14$ & MG (350 grains) & $11 / 12$ & $1.38 \pm 0.11$ & -0.02 & \pm 1.48 & $4 \pm 1$ & $943 \pm 15$ & $417 \pm 27$ & $937 \pm 47$ & $415 \pm 33$ & $942 \pm 47$ & $417 \pm 34$ \\
\hline SH12-3A & 0.53 & $90-125$ & $2.26 \pm 0.12$ & MG (350 grains) & $12 / 12$ & $1.19 \pm 0.06$ & 0.33 & \pm 1.41 & $4 \pm 1$ & $971 \pm 14$ & $430 \pm 25$ & $939 \pm 28$ & $415 \pm 26$ & $970 \pm 24$ & $429 \pm 26$ \\
\hline SH12-2A & 0.83 & $90-125$ & $2.20 \pm 0.12$ & MG (350 grains) & $11 / 12$ & $1.62 \pm 0.06$ & -0.08 & \pm 1.48 & $5 \pm 1$ & $940 \pm 17$ & $428 \pm 27$ & $907 \pm 31$ & $413 \pm 29$ & $938 \pm 32$ & $427 \pm 30$ \\
\hline \multicolumn{16}{|c|}{ Sima ramp bottom (SRB) } \\
\hline SH12-1A & 0.33 & $90-125$ & $2.09 \pm 0.10$ & MG (350 grains) & $12 / 12$ & $1.71 \pm 0.10$ & 0.90 & \pm 1.41 & $7 \pm 2$ & $923 \pm 21$ & $441 \pm 25$ & $896 \pm 31$ & $428 \pm 27$ & $898 \pm 35$ & $429 \pm 28$ \\
\hline
\end{tabular}

${ }^{\text {a }} D_{\mathrm{e}}$ type: MG (350 grains) $=$ multi-grain aliquots containing $\sim 350$ grains each.

${ }^{b}$ Number of $D_{\mathrm{e}}$ measurements that passed the SAR rejection criteria/total number of multi-grain aliquots analysed.

c Weighted skewness scores have been calculated on log-transformed $D_{\mathrm{e}}$ values using Eqs. (7)-(8) of Arnold and Roberts (2009).

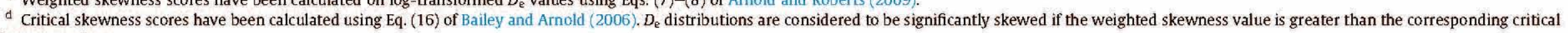
skewness value.

e $\mathrm{CAM}=$ central age model, MAM-3 = 3-parameter minimum age model, MAM-4 = 4-parameter minimum age model (Galbraith et al., 1999).

f Mean \pm total uncertainty ( $68 \%$ confidence interval), calculated as the quadratic sum of the random and systematic uncertainties.

$g$ Total uncertainty includes a systematic component of $\pm 2 \%$ associated with laboratory beta-source calibration.

${ }^{n}$ Final pIR-IR ages (shown in bold) have been calculated using the CAM $D_{\mathrm{e}}$ for these multi-grain aliquot measurements (see main text for details).

i The modern analogue sample was collected from surface sediments for the purpose of assessing residual $D_{\mathrm{e}}$ values in this sedimentary context. Since

we have not calculated a final age. The fading rate $\left(g_{2 \text { days }}\right)$ was also not measured for this sample. 
Table 5

Summary statistics for the TT-OSL $D_{\mathrm{e}}$ measurements, age model results and final ages of the Sima de los Huesos samples.

\begin{tabular}{|c|c|c|c|c|c|c|c|c|c|c|c|c|c|c|}
\hline \multirow[t]{2}{*}{ Sample } & \multirow{2}{*}{$\begin{array}{c}\text { Sample } \\
\text { depth } \\
\text { (m) }\end{array}$} & \multirow{2}{*}{$\begin{array}{l}\text { Grain } \\
\text { size } \\
(\mu \mathrm{m})\end{array}$} & \multirow{2}{*}{$\begin{array}{c}\text { Total dose } \\
\text { rate } \\
(\mathrm{Gy} / \mathrm{ka})\end{array}$} & \multirow{2}{*}{$\begin{array}{l}D_{\mathrm{e}} \text { type and } \\
\text { resolution }\end{array}$} & \multirow{2}{*}{$\begin{array}{l}\text { Accepted/ } \\
\text { measured } \\
D_{\mathrm{e}} \text { values }^{\mathrm{b}}\end{array}$} & \multirow{2}{*}{$\begin{array}{l}\text { Weighted } \\
\text { skewness }^{c}\end{array}$} & \multirow{2}{*}{$\begin{array}{c}\text { Critical } \\
\text { skewness } \\
(95 \% \text { C.I. })^{d}\end{array}$} & \multicolumn{3}{|c|}{ CAM results $^{\mathrm{e}}$} & \multicolumn{4}{|c|}{ FMM results ${ }^{e, i}$} \\
\hline & & & & & & & & $\begin{array}{l}\text { Overdispersion } \\
(\%)\end{array}$ & $\begin{array}{c}\text { CAM } \\
\mathrm{D}_{\mathrm{e}}(\mathrm{Gy})^{f}\end{array}$ & $\begin{array}{c}\text { CAM } \\
\text { age }(\mathrm{ka})^{\mathrm{f}, \mathrm{h}, \mathrm{h}}\end{array}$ & $\begin{array}{c}\text { FMM } \\
\text { components }\left(K_{\mathrm{n}}\right)\end{array}$ & $\begin{array}{l}\text { Proportion } \\
\text { of grains (\%) }\end{array}$ & $\begin{array}{c}\text { FMM } \\
\mathrm{D}_{\mathrm{e}}(\mathrm{Gy})^{\mathrm{f}}\end{array}$ & $\begin{array}{c}\text { FMM } \\
\text { age }(\mathrm{ka})^{\mathrm{f} .8}\end{array}$ \\
\hline \multicolumn{15}{|c|}{ Modem analogue sample } \\
\hline \multicolumn{15}{|c|}{ Sima ramp middle (SRM) } \\
\hline $\mathrm{SH} 12-4 \mathrm{~A}$ & 0.35 & $90-125$ & $1.80 \pm 0.13$ & SG (18 grains) & $39 / 1500$ & -0.12 & \pm 0.78 & $22 \pm 5$ & $767 \pm 41$ & $426 \pm 39$ & $K_{1}$ & 100 & $768 \pm 41$ & $426 \pm 39$ \\
\hline \multirow[t]{2}{*}{ SH12-3A } & 0.53 & $90-125$ & $1.80 \pm 0.11$ & SG (18 grains) & $70 / 2300$ & -0.81 & \pm 0.59 & $42 \pm 5$ & $713 \pm 42$ & $396 \pm 35$ & $K_{1}$ & $15 \pm 6$ & $319 \pm 46$ & $177 \pm 28$ \\
\hline & & & & & & & & & & & $K_{2}$ & $85 \pm 6$ & $844 \pm 43$ & $468 \pm 39$ \\
\hline \multicolumn{15}{|c|}{ Sima ramp bottom (SRB) } \\
\hline SH12-1A & 0.33 & $90-125$ & $1.63 \pm 0.10$ & SG (18 grains) & $54 / 1400$ & -0.26 & \pm 0.67 & $19 \pm 5$ & $701 \pm 31$ & $429 \pm 32$ & $K_{1}$ & 100 & $700 \pm 31$ & $429 \pm 32$ \\
\hline
\end{tabular}

${ }^{a} D_{\mathrm{e}}$ type: MG (1100 grains) = multi-grain aliquots containing $\sim 1100$ grains each, SG (18 grains) = single-grain measurements containing $\sim 18$ grains per grain-hole position.

${ }^{b}$ Number of $D_{\mathrm{e}}$ measurements that passed the SAR rejection criteria/total number of grains or multi-grain aliquots analysed.

${ }^{c}$ Weighted skewness scores have been calculated on log-transformed $D_{\mathrm{e}}$ values using Eqs. (7)-(8) of Arnold and Roberts (2009).

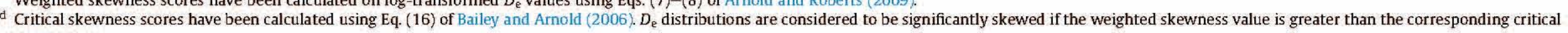
skewness value.

${ }^{e}$ CAM = central age model (Galbraith et al., 1999), FMM = finite mixture model (Galbraith and Green, 1990).

${ }^{\mathrm{f}}$ Mean \pm total uncertainty ( $68 \%$ confidence interval), calculated as the quadratic sum of the random and systematic uncertainties.

${ }^{g}$ Total uncertainty includes a systematic component of $\pm 2 \%$ associated with laboratory beta-source calibration.

${ }^{\mathrm{h}}$ Final ages (shown in bold) have been calculated using the CAM $D_{\mathrm{e}}$ for these single-grain TT-OSL measurements (see main text for details).

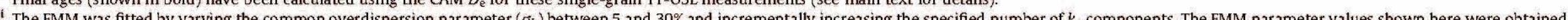

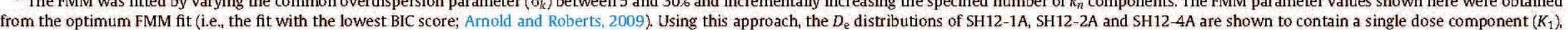

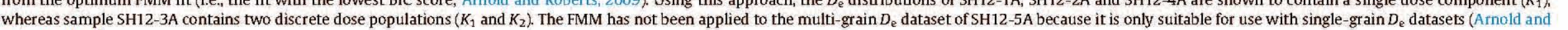
Roberts, 2009).

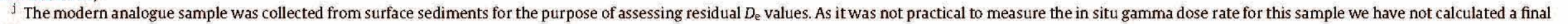
age. 
Magnetometer (Micromag 3900 VSM). Specimens were stored in a $\mu$-metal shielded cylindrical can during analysis to prevent acquisition of viscous magnetisation.

In addition to acquiring the primary magnetisation, it is well known that rocky materials can acquire secondary magnetisations as a result of natural processes such as weathering, heating for an extended time and diagenesis. Moreover, materials can be artificially magnetised by proximity to strong magnetic fields during sampling, drilling, transportation, and storage. One of the major tasks in any palaeomagnetic study is to resolve the Natural Remanent Magnetisation, i.e., the sum of all magnetisations carried by a rock, into its constituent primary and secondary components. For this purpose, both thermal and alternating field demagnetisation were used to isolate the Characteristic Remanent Magnetisation (ChRM) component. The ChRM directions were calculated for all specimens using Principal Component Analysis (Kirschvink, 1980), guided by visual inspection of orthogonal demagnetisation plots (Zijderveld, 1967). Mean directions and associated statistical parameters were estimated using Fisher's (1953) method (dispersion $k$ and confidence angle $\alpha_{95}$ ).

\section{Luminescence dating results and analyses}

\section{Luminescence characteristics}

Representative pIR-IR $225 /$ TT-OSL decay curves and doseresponse curves for grains/aliquots that passed the SAR quality assurance criteria are shown in Fig. 4. The pIR-IR $225 L_{n}$ signals typically decay to $<5 \%$ of initial intensities within the first $100-$ $150 \mathrm{~s}$ of stimulation and reach stable background levels within the last 50 s of stimulation (e.g., Fig. 4a). The associated pIR-IR 225 multigrain aliquot dose-response curves are generally well-represented by either a single saturating exponential function or a saturating exponential plus linear function. The accepted quartz grains typically display $T_{\mathrm{n}}(200 \mathrm{~Gy})$ TT-OSL signals of $100-500 \mathrm{cts} / 0.17 \mathrm{~s}$ (e.g., Fig. 4b). However, all samples contain a small number of relatively bright accepted grains (e.g., Fig. $4 \mathrm{c}$ ) displaying $T_{\mathrm{n}}$ TT-OSL signal intensities $>1000$ counts/0.17 s (Fig. S1b). Single-grain TT-OSL dose-response curves display more intra-sample variability than their multi-grain aliquot pIR-IR 225 counterparts but are generally characterised by continued signal growth at very high $\left(10^{3} \mathrm{~Gy}\right)$ doses and are well-represented by a single saturating exponential function (e.g., Fig. 4b-c).

\section{Modern analogue residual doses}

Tables 4 and 5 summarise the $D_{\mathrm{e}}$ values and age estimates obtained for the Sima samples. Also included in these tables are the weighted mean $D_{\mathrm{e}}$ results obtained for the modern sample (SH12$5 A$ ) collected outside the cave mouth. The average pIR-IR 225 and TTOSL residual doses for this sample are $7.3 \pm 0.8 \mathrm{~Gy}$ and $7.3 \pm 1.2 \mathrm{~Gy}$, respectively. These natural $D_{\mathrm{e}}$ residuals are comparable with those obtained for modern aeolian samples in previous TT-OSL studies (e.g., Wang et al., 2006a; Porat et al., 2009; Stevens et al., 2009) and previous pIR-IR 225 studies (e.g., Thomsen et al., 2008; Buylaert et al., 2009). They are also consistent with the range of residual IRSL doses measured for a wider range of present-day surface sediments in the surroundings of the Sierra de Atapuerca (Berger et al., 2008). The residual $D_{e}$ values of SH12-5A are largely inconsequential in comparison with the empirical $D_{\mathrm{e}}$ values measured for the Sima samples; equating to $<1 \%$ of the weighted mean quartz $D_{\mathrm{e}}$ values and $<0.7 \%$ of the weighted mean K-feldspar $D_{\mathrm{e}}$ estimates for samples SH12-1A to SH12-4A. As such, we have not considered an additional residual dose subtraction in the age estimates presented in Tables 4 and 5 . These results provide good support for the potentially well-bleached nature of the Sima source sediments prior to their transportation into the cave system. The residual $D_{e}$ values would correspond to age offsets of only $\sim 3-4$ ka if the Sima sample had been sourced from similar surface deposits in the past. Any such systematic biases would be well within the existing $1 \sigma$ uncertainties of our final ages.

pIR-IR $225 D_{e}$ results

The multi-grain aliquot K-feldspar $D_{\mathrm{e}}$ distributions (Fig. 5) each cover a fairly limited range of doses (relative $D_{\mathrm{e}}$ range $=0.16-0.32$ ); they are consistent with a single dose population centred on the weighted mean $D_{\mathrm{e}}$ value (as indicated by the large proportion of aliquots lying within the grey bands in Fig. 5) and they are not considered to be significantly skewed at the $95 \%$ C.I. when assessed using a log weighted skewness test (Arnold and Roberts, 2009, 2011). The $D_{\mathrm{e}}$ distributions all display very low overdispersion values of $4-7 \%$ (Table 4 ), which suggests that any dose dispersion originating from sources such as partial bleaching are relatively unimportant in relation to the size of the existing $D_{\mathrm{e}}$ measurement uncertainties. While it is difficult to rule out multi-grain averaging effects in any multi-grain aliquot study (e.g., Demuro et al., 2008, 2013; Arnold and Roberts, 2009; Arnold et al., 2013), the apparently fully bleached nature of these samples is consistent with the multi-grain aliquot results obtained for the modern analogue. Moreover, the effects of any undetectable, averaged-out residual doses should be relatively minor in this instance given the very large doses absorbed by the sediments during their prolonged burial periods. In light of these multi-grain aliquot $D_{\mathrm{e}}$ characteristics, we have estimated the final burial doses from each sample's weighted mean $D_{\mathrm{e}}$ estimate, calculated using the central age model (CAM) of Galbraith et al. (1999). For comparative purposes, Table 4 also shows the $D_{\mathrm{e}}$ values and corresponding ages obtained using the 3- and 4-parameter minimum age models (MAM-3, MAM-4) of Galbraith et al. (1999). The MAM-3 and MAM-4 pIR-IR 225 ages are consistent with their CAM counterparts at $1 \sigma$ for all four Sima samples, indicating that our final chronologies are insensitive to age model choice or assumptions concerning bleaching history.

\section{pIR-IR225 fading tests}

To assess the long-term (athermal) stability of the pIR-IR 225 signal, we undertook anomalous fading measurements on three of the aliquots used to derive $D_{\mathrm{e}}$ values for each sample. Laboratory fading rates were measured using the pIR-IR ${ }_{225}$ SAR protocol shown in Table 2a, following the procedure suggested by Auclair et al. (2003). After $D_{\mathrm{e}}$ measurements were completed, aliquots were subjected to a series of nine repeated SAR $L_{x} / T_{x}$ measurements that included different storage periods after each regenerative-dose preheat step (i.e., between steps 2 and 3 in Table $2 \mathrm{a}$ ). The storage times included in these repeat $L_{x} / T_{x}$ cycles varied between 'prompt' measurements of $0.17 \mathrm{~h}$ to maximum delays of $24 \mathrm{~h}$. The total delay times used to calculate fading rates comprise half of the $L_{x}$ irradiation time, the intervening preheating and thermal ramping times, carousel rotation times between measurements, and the storage periods. Empirical fading rates were quantified in terms of the $g$ value (Aitken, 1985), which expresses the percentage decrease in sensitivity-corrected pIR-IR signal per decade of storage time since irradiation. The $g$-values were determined from the repeated $L_{x} / T_{x}$ values using Eq. (4) of Huntley and Lamothe (2001), and were subsequently normalised to a measurement delay time of two days ( $\left.g_{2 \text { days }}\right)$ to enable direct comparisons with previously published values.

The pIR-IR 225 laboratory fading rates obtained for the Sima samples are all very low (Table 4). Weighted mean $g$-values for each 

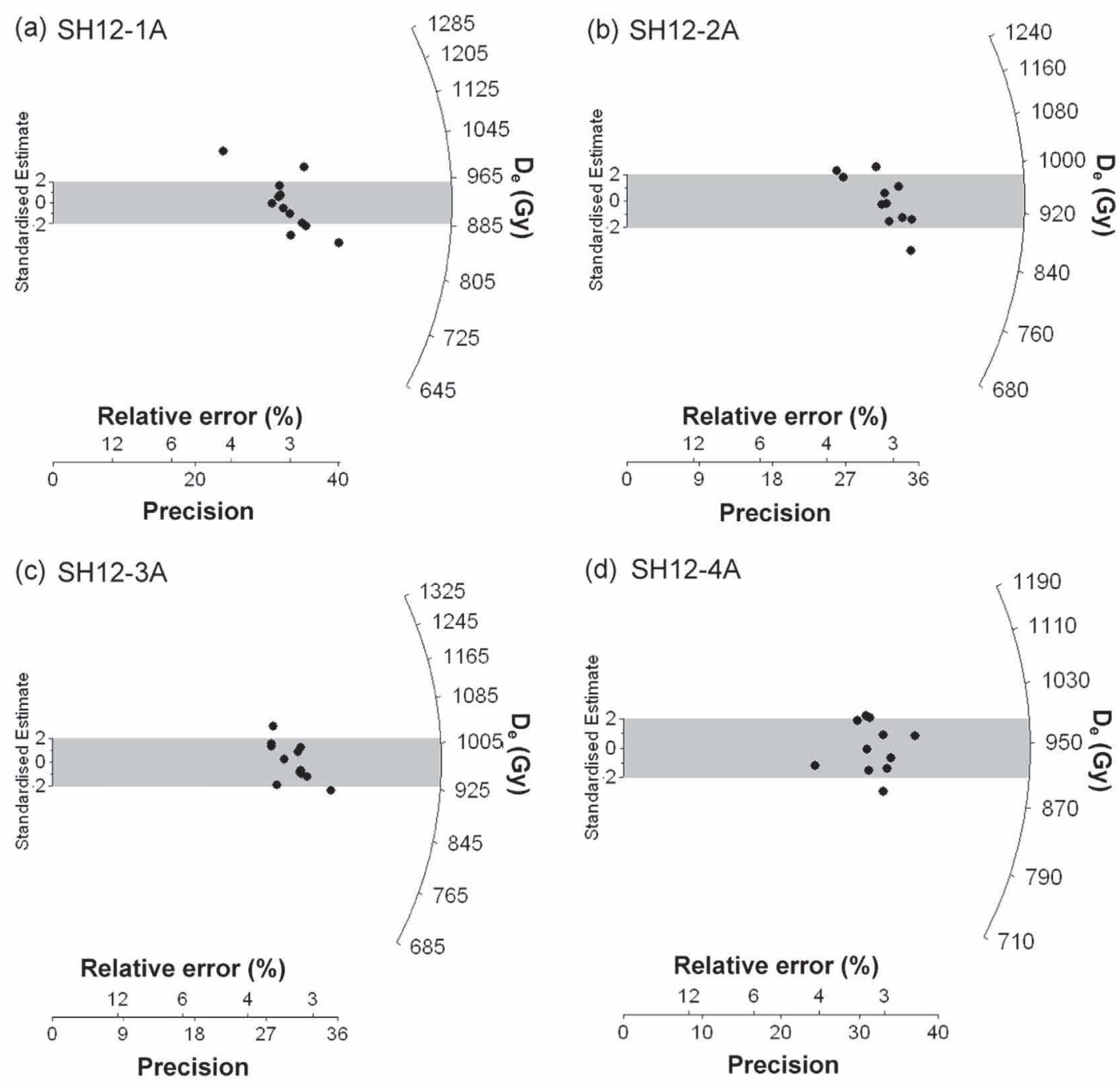

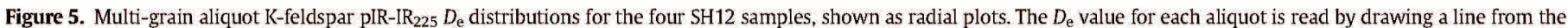

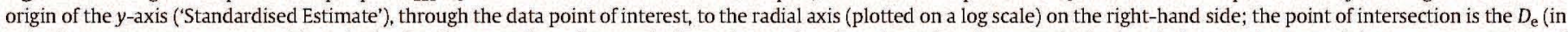

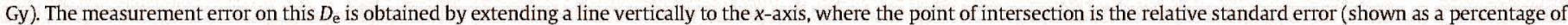

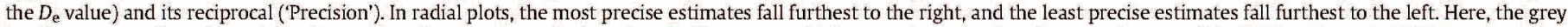
bands are centred on the weighted mean $D_{\mathrm{e}}$ values used to calculate the pIR-IR 225 ages, which we estimated using the central age model of Galbraith et al. (1999).

sample ranged between $1.19 \pm 0.07 \%$ and $1.71 \pm 0.10 \%$ decade, and the combined weighted average $g$-values for all individual aliquots $(n=12)$ was $1.47 \pm 0.07 \% /$ decade. By comparison, weighted mean $g$-values obtained using the conventional IRSL signal (measured as part of the pIR-IR 225 SAR protocol: IR $_{50 / 225}$ ) were much higher, ranging between $2.75 \pm 0.26 \%$ and $3.52 \pm 0.14 \%$ /decade per sample. These results are consistent with previous observations (e.g., Thomsen et al., 2008; Buylaert et al., 2009), which suggest that pIRIR signals are inherently more stable than conventional IRSL signals. The pIR-IR 225 -values are also in good agreement with previously published pIR-IR 225 fading rates, which typically vary between $\sim 1-2 \%$ /decade (e.g., Thomsen et al., 2008; Buylaert et al., 2009, 2011; Kars et al., 2012; Lowick et al., 2012; Roberts, 2012; Vasiliniuc et al., 2012).

A number of studies have demonstrated good agreement between pIR-IR 225 ages that have not been corrected for fading and associated age control for samples that display $g$-values of $1-2 \%$ / decade (e.g., Gliganic et al., 2012b; Kars et al., 2012; Roberts, 2012). In several cases, uncorrected pIR-IR 225 ages appear equally, if not more, reliable in comparison to uncorrected pIR-IR 290 ages for known-age samples (Buylaert et al., 2011; Lowick et al., 2012; Roberts, 2012; Vasiliniuc et al., 2012). It is worth noting that replicate $\mathrm{pIR}-\mathrm{IR}_{225}$ and $\mathrm{pIR}-\mathrm{IR}_{290}$ fading rates reported so far in the literature for the same samples are statistically indistinguishable from each other at $2 \sigma$ (e.g., Buylaert et al., 2011; Lowick et al., 2012; Roberts, 2012; Vasiliniuc et al., 2012). Additionally, there is evidence to suggest that natural pIR-IR 290 (and pIR-IR 225 ) signals can reach field-saturation in some samples and are therefore seemingly unaffected by anomalous fading (e.g., Buylaert et al., 2011; Thiel et al., 2011; Kars et al., 2012; Vasiliniuc et al., 2012). These collective observations have led to suggestions that the very low $g$-values measured for pIR-IR signals are likely to be an artefact of laboratory measurement procedures (e.g., they could be caused by unreliable sensitivity correction following storage) and that they do not necessarily provide reliable estimates of anomalous fading (e.g., Buylaert et al., 2012; Roberts, 2012). If this is the case, fading corrections based on potentially problematic $g$-value assessments may actually introduce additional age uncertainties. Additional support for this interpretation comes from $g$-value measurements performed on quartz, which does not typically suffer from anomalous fading. Empirical $g$-values measured for various quartz samples by Thiel et al. (2011) and Buylaert et al. (2012) ranged between 0.8$1.9 \% /$ decade at $2 \sigma$, suggesting that pIR-IR fading rates may be overestimated by a similar order of magnitude. 
(a) $\mathrm{SH} 12-1 \mathrm{~A}$

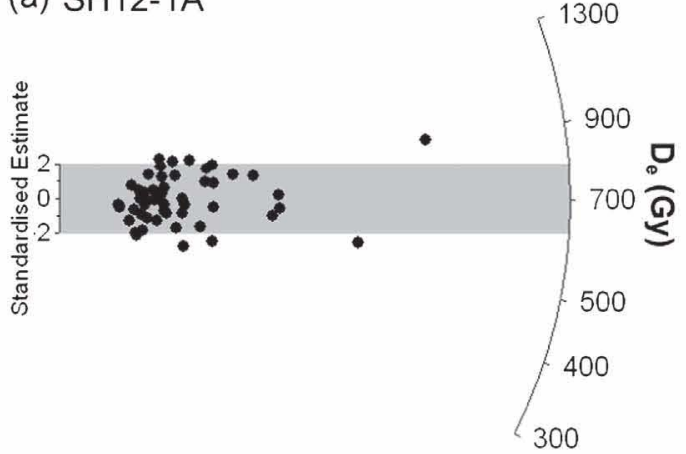

\section{Relative error (\%)}

\begin{tabular}{lllll} 
& 36 & 18 & 12 & 9 \\
\hline 0 & 4 & 8 & 12 \\
& & & Precision &
\end{tabular}

(c) $\mathrm{SH} 12-3 \mathrm{~A}$

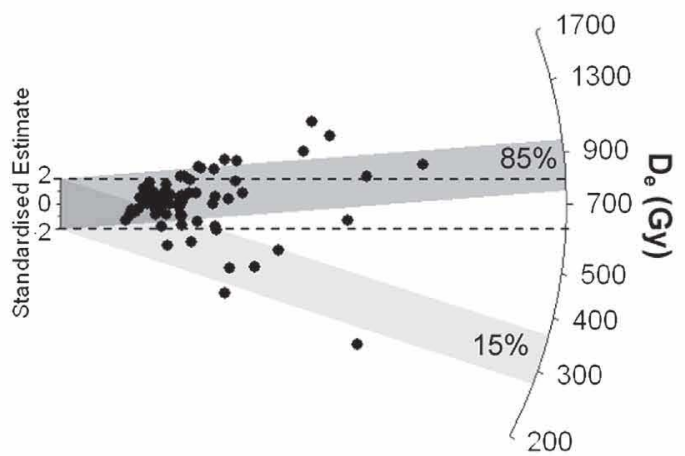

\begin{tabular}{|cccc}
\multicolumn{4}{c}{ Relative error (\%) } \\
36 & 18 & 12 & 9 \\
\hline $0 \quad 3$ & 6 & 9 & 12 \\
Precision &
\end{tabular}

(b) $\mathrm{SH} 12-2 \mathrm{~A}$

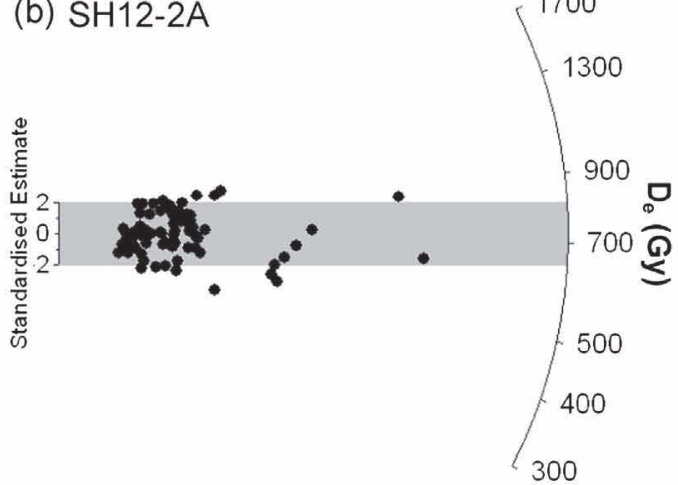

Relative error (\%)

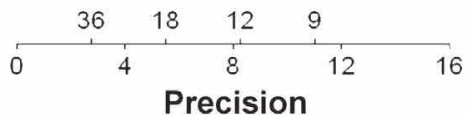

(d) $\mathrm{SH} 12-4 \mathrm{~A}$
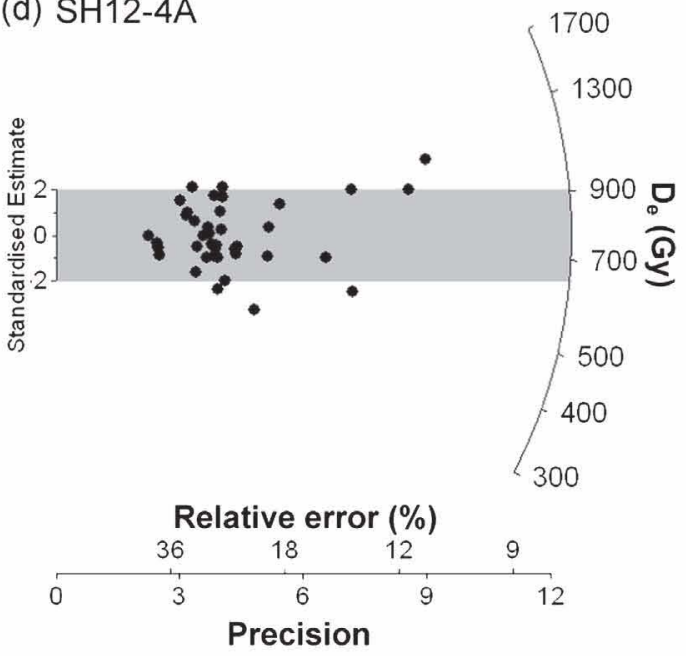

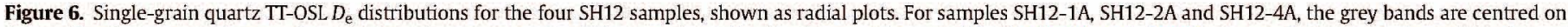

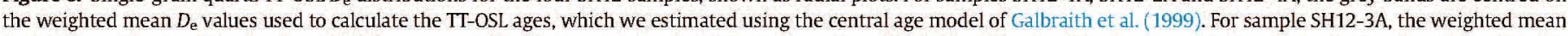

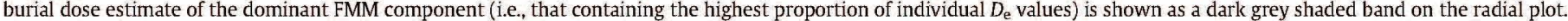

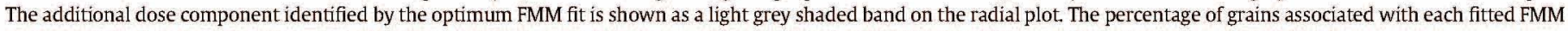
component is also shown on the radial plots. The weighted mean $D_{\mathrm{e}}$ value used to calculate the TT-OSL age of this sample is shown as a dashed band.

The low pIR-IR 225 fading rates obtained in the present study (Table 4) suggest that the signal being used for dating is potentially as stable as that reported elsewhere for PIR-IR 290 and quartz OSL procedures. Taking into consideration this factor, as well as published evidence suggesting that such low empirical fading rates may be unreliable or artefacts of laboratory procedures (e.g., Buylaert et al., 2012; Lowick et al., 2012; Roberts, 2012, Vasiliniuc et al., 2012), we have not applied a fading correction to the final pIR-IR 225 ages of the Sima samples.

\section{TT-OSL $D_{e}$ results}

Samples SH12-1A, SH12-2A and SH12-4A share similar, homogeneous single-grain TT-OSL $D_{\mathrm{e}}$ distributions (Fig. 6a,b,d) characterised by moderate dose dispersion (relative $D_{\mathrm{e}}$ range $=1.3-1.4$ ), single dose populations that are not significantly skewed according to the criterion outlined by Arnold and Roberts (2011), $D_{\mathrm{e}}$ scatter that is well-represented by the weighted mean band at $2 \sigma$, and low overdispersion values of $20-23 \%$ (Table 5). The individual overdispersion estimates are all consistent with a value of $<20 \%$ at $1 \sigma$ and $<15 \%$ at $2 \sigma$, and are in agreement with published single-grain OSL overdispersion datasets for ideal, well-bleached sedimentary samples that have not been affected by post-depositional mixing (see summary in Arnold and Roberts, 2009). The single-grain TTOSL radial plots do not display distinct 'leading-edges' of low $D_{e}$ values or elongated, asymmetric 'tails' of higher $D_{\mathrm{e}}$ values, which are characteristic of partially bleached single-grain $D_{e}$ distributions (e.g., Olley et al., 1999, 2004; Arnold et al., 2007, 2009). Any residual doses arising from insufficient bleaching therefore appears to have been relatively minor compared with the large burial doses accumulated by these deposits. The absence of multiple dose components in the single-grain $D_{\mathrm{e}}$ distributions (Table 5) also suggests that sediment mixing (e.g., Arnold et al., 2013) and beta-dose heterogeneity in the natural burial environment (e.g., Jacobs et al., 2008) are unimportant. Finally, the single-grain TT-OSL $D_{\mathrm{e}}$ distributions are consistent with the corresponding multi-grain aliquot pIR-IR $225 D_{\mathrm{e}}$ characteristics for these three samples, lending further support to the interpretation that these samples were fully bleached prior to deposition and remained in situ thereafter. We have therefore used the CAM to derive representative burial dose estimates and final ages. Multi-grain ( 1100 grain) aliquot TT-OSL measurements made on sample $\mathrm{SH} 12-2 \mathrm{~A}$ yielded a weighted mean natural $D_{\mathrm{e}}$ value of $795 \pm 97 \mathrm{~Gy}(n=5)$ and a corresponding age of $458 \pm 65 \mathrm{ka}$. Both the single-grain and multi-grain aliquot replicate 
ages for this sample are consistent at $1 \sigma$ (Table 5), providing added confidence in the final burial dose estimates.

The single-grain TT-OSL $D_{\mathrm{e}}$ distribution for sample SH12-3A is distinctly different from its neighbouring samples (Fig. $6 \mathrm{c}$ ). This $D_{\mathrm{e}}$ dataset displays a large amount of scatter (relative $D_{\mathrm{e}}$ range $=1.7$ ) and a significant proportion of individual $D_{\mathrm{e}}$ values fall outside the $2 \sigma$ standardised estimate of the CAM burial dose. The $D_{\mathrm{e}}$ distribution also shows statistically significant negative skewness at 95\% C.I. and has a higher overdispersion value of $42 \%$. Application of the finite mixture model (FMM) (Galbraith and Green, 1990) using the implementation procedure outlined in the supplementary information of Arnold et al. (2013) confirmed the presence of multiple dose populations in this dataset. The results of the optimum FMM fit (obtained using an overdispersion parameter of $20 \%$; which is consistent with empirical values obtained for the well-bleached, unmixed $D_{e}$ datasets of samples SH12-1A, 2A and 4A) are summarised in Table 5 and reveals two discrete burial dose populations: a major dose population (containing $85 \%$ of $D_{\mathrm{e}}$ values) centred on $844 \pm 43 \mathrm{~Gy}$, and a smaller component (containing $15 \%$ of $D_{\mathrm{e}}$ values) with a mean dose of $319 \pm 46 \mathrm{~Gy}$ (Fig. 6c). Various extrinsic (field-related) and/or intrinsic (experimentally derived) sources of $D_{\mathrm{e}}$ scatter could explain the presence of these two discrete dose populations, and these factors are discussed in further detail in the SOM. Taking into consideration the stratigraphic context, sedimentary history and $D_{\mathrm{e}}$ characteristics of SH12-3A (and bracketing samples), we would suggest that spatial variations in the beta dose rate experienced by individual grains could explain the high dose overdispersion of this sample.

Assuming that the two discrete dose components of SH12-3A can be explained by small-scale differences in beta dose rates, it follows that the bulk (sample-average) dose rate will not be representative of that experienced by either dose component during burial. There are differing views on how to derive appropriate age estimates from such complex $D_{\mathrm{e}}$ datasets, namely whether to calculate beta-adjusted dose rates for separate dose components (e.g., Jacobs et al., 2008) or whether to use the sample-averaged beta dose rate in conjunction with a weighted mean $D_{\mathrm{e}}$ estimate for the combined $D_{\mathrm{e}}$ dataset (e.g., Guérin et al., 2013). We have applied these two approaches to the SH12-3A D dataset and both yield consistent TT-OSL age estimates. Specifically, the CAM age derived using the approach of Guérin et al. (2013) (396 $\pm 35 \mathrm{ka}$ ) overlaps at $1 \sigma$ with the FMM age obtained for the main dose component using either the sample-average dose rate ( $468 \pm 39 \mathrm{ka}$; Table 5) or the beta-adjusted dose rate calculation of Jacobs et al. (2008) (445 $\pm 38 \mathrm{ka})$. Deriving component-specific environmental dose rates for the two FMM dose populations remains an open-ended problem in the present context, since there are too many unconstrained parameters to retrospectively reconstruct accurate in situ dose rate geometries for the measured grains. In the absence of a more definitive solution, therefore, we have pragmatically used the CAM $D_{\mathrm{e}}$ and sample-averaged beta dose rate to derive the final age estimate for this sample. The overall consistency of the results obtained using the approaches of Jacobs et al. (2008) and Guérin et al. (2013) provides us with confidence that our final age model selection is reliable within empirical uncertainties.

\section{Palaeomagnetic results and analyses}

Most of the clay samples taken from the café con leche and fossiliferous red clay units showed stable behaviour during demagnetisation, leading to an accepted-to-measured specimen ratio of 0.8 (Table 1). Both alternating field (AF) and thermal demagnetisation produced similar results, hence the former was chosen for the majority of the samples collected. Maximum AF peak fields of about $40 \mathrm{mT}$ or temperatures of around $500^{\circ} \mathrm{C}$ were high enough to isolate the ChRM directions in the clay samples (Fig. 7a and b). These observations suggest that magnetite is the main carrier of stable remanence in the sediments, consistent with previous results for similar sediments from the Trinchera de Atapuerca sites (e.g., Parés and Pérez-González, 1995, 1999; Parés et al., 2010), and from other cave deposits (e.g., Bosák and Pruner, 2011). The hysteresis curves are also indicative of a low coercivity magnetic phase, and the associated $M_{\mathrm{r}} / M_{\mathrm{s}}$ and $H_{\mathrm{cr}} / H_{\mathrm{c}}$ ratios reveal magnetite in the pseudo-single domain (Fig. 8a). The ChRM directions for the café con leche clays, hominin-bearing upper red clays and sterile lower red clays are north directed and have positive inclination, producing Virtual Geomagnetic Pole positions that cluster around the north geomagnetic pole. The normal polarities for these sediments are consistent with the luminescence dating results obtained on the café con leche horizons and fossil evidence for a Middle Pleistocene age for the red clay deposits (Bischoff et al., 1997; Cuenca-Bescós et al., 1997; García et al., 1997; García and Arsuaga, 2011). The palaeomagnetic results therefore confirm that the hominin fossil horizon accumulated during the Brunhes Chron, and is younger than $780 \mathrm{ka}$.

The ST and SRA flowstone samples were also generally wellbehaved upon thermal or alternating field demagnetisation. Typically, a soft component was removed by $10 \mathrm{mT}$ or $150^{\circ} \mathrm{C}$, above which the demagnetisation decayed linearly towards the origin in the Zijderveld diagrams (Fig. 7c). Both thermal and alternating field demagnetisation produced similar ChRM directions. In all cases, the ChRM directions are north directed and have positive inclinations. The palaeomagnetic directions recorded by the LU-10, LU-8 and LU-2 flowstones are all statistically indistinguishable from the expected reference direction for a normal polarity pole during the Pleistocene, which suggests that these speleothems have not been tilted (horizontally or vertically) since their formation and most likely formed in their present locations and orientations. Maximum unblocking temperatures $\left(590^{\circ} \mathrm{C}\right)$, median destructive field, and IRM acquisition curves (Fig. 8b) suggest the presence of magnetite as the main ferromagnetic mineral responsible for the remanence. These trends are consistent with previous results obtained for other flowstones from neighbouring Atapuerca archaeological sites (e.g., Parés and Pérez-González, 1995, 1999; Parés et al, 2010), as well as with speleothem rock-magnetism studies undertaken elsewhere(Latham and Ford, 1993; Perkins and Maher, 1993). These observations provide us with confidence that the magnetisation of the sediments and flowstones is primary rather than secondary, and reflects the polarity of the geomagnetic field at the time of deposition. As such, the palaeomagnetic samples are considered suitable for geochronological purposes. In the case of speleothems LU-10 and LU-8, which overlie the luminescence dated café con leche horizon, the normal polarity results can be confidently interpreted as corresponding to the Brunhes Chron. Ascertaining a corresponding geomagnetic chron for the underlying speleothem (LU-2) at ST is less straightforward. The palaeomagnetic directions for speleothem LU-2 are consistent with formation during the Brunhes Chron, but we cannot rule out the possibility that they may pertain to a subchron (e.g. Jaramillo, Cobb Mountain) or a shorter-lived normal polarity event (e.g., Santa Rosa, Kamikatsura) within the Matuyama Chron.

\section{Discussion}

\section{Revised minimum age constraint for the Sima hominin fossils}

Both the TT-OSL and pIR-IR 225 chronological datasets are internally consistent and statistically indistinguishable at $1 \sigma$ (Tables 4 and 5). Replicate TT-OSL and pIR-IR 225 ages obtained for individual samples are also in agreement at $1 \sigma($ Fig. $2 \mathrm{c}$ ), lending support to 


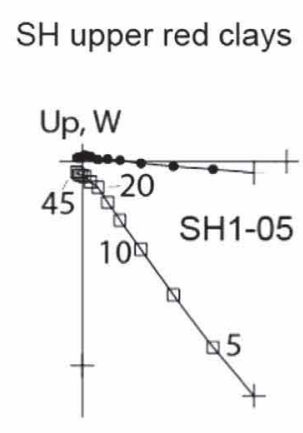

$\mathrm{NRM}=0.141 \mathrm{E}-1 \mathrm{~A} / \mathrm{m}$

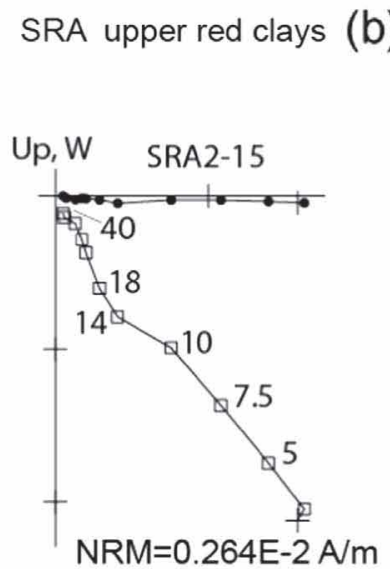

Up, W

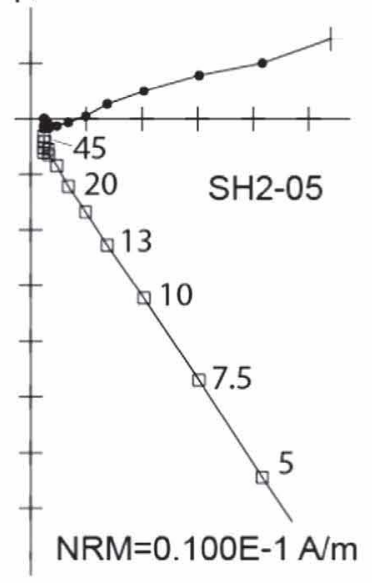

SRA flowstone LU-10

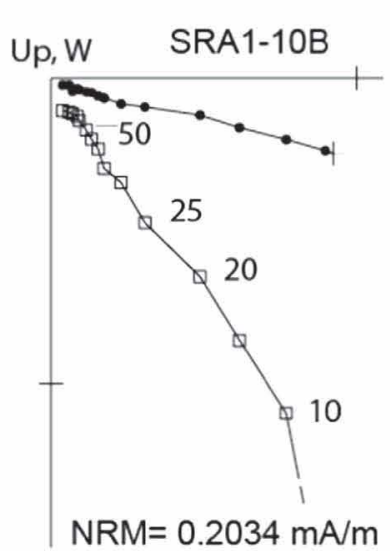

(a)

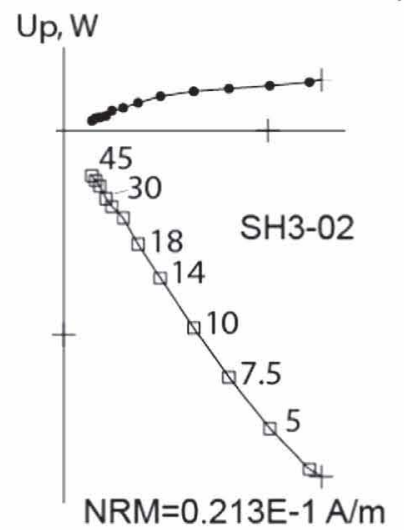

(c)

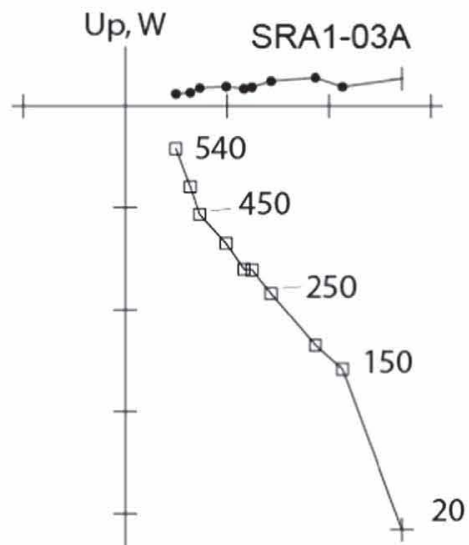

$\mathrm{NRM}=0.4973 \mathrm{~mA} / \mathrm{m}$

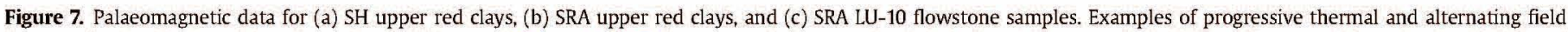

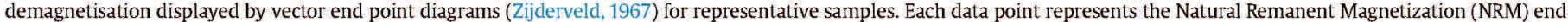

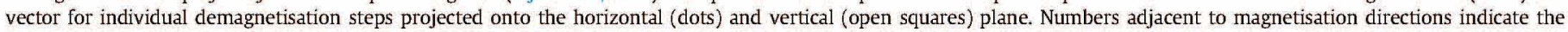
demagnetisation temperature in degrees Celsius or AF demagnetisation peak in miliTesla. Initial value of NRM (in $\mathrm{mA} / \mathrm{m}$ ) is also shown.

the reliability of our extended-range luminescence dating approaches at this site. The lack of a distinguishable age-depth profile for the three café con leche samples reveals a relatively rapid accumulation by one or more depositional episodes spanning a period that is shorter than our empirical error ranges. The internal consistency of the two chronological datasets permits calculation of a weighted mean TT-OSL age of $416 \pm 19 \mathrm{ka}$ and a weighted mean pIR-IR 225 age of $433 \pm 15$ ka for the café con leche unit. The pooled weighted mean luminescence age for this horizon $(n=6)$ is therefore $427 \pm 12 \mathrm{ka}$. These results indicate sediment deposition during early Marine Isotope Stage (MIS) 11 or the terminal stages of late MIS 12 (Lisiecki and Raymo, 2005), and provide corresponding minimum age estimates for the underlying red clay archaeological horizon.

There has been some debate in the literature over the thermal stability of the TT-OSL signal and, in particular, whether the lifetime of the TT-OSL trap is sufficient enough to enable reliable age determination over Middle to Early Pleistocene timescales in different thermal environments (e.g., Adamiec et al., 2010; Jacobs et al., 2011; Duller and Wintle, 2012; Thiel et al., 2012). Adamiec et al. (2010) calculated an electron-retention lifetime for the TTOSL source trap of $\sim 4.5 \mathrm{Ma}$ at a storage temperature of $10^{\circ} \mathrm{C}$.
This predicted lifetime is three orders of magnitude lower than for the source trap giving rise to the conventional (fast component) OSL signal and implies that TT-OSL ages may underestimate true burial ages by $\sim 10 \%$ for a 1 Ma sample experiencing a long-term burial temperature of $10{ }^{\circ} \mathrm{C}$. However, the uncertainties associated with laboratory derived estimates of trap lifetimes (which are typically not quoted) are likely to be particularly broad owing to the difficulties of accurately and precisely measuring kinetic parameters with standard luminescence measurements (Aitken, 1985, Duller and Wintle, 2012). It is also unclear whether the limited number of laboratory lifetime measurements made so far adequately reflects possible variations in TT-OSL thermal stabilities between samples from different geological provenances, and - in the case of single-grain TT-OSL measurements - whether they are suitably representative of inter-grain variations within a given sample. Indeed, accurate TT-OSL ages have been reported for a range of Early and Middle Pleistocene samples that either have associated independent age control (e.g., Wang et al., 2006a; Sun et al., 2010; Arnold et al., 2013; Pickering et al., 2013) or have comparative conventional luminescence chronologies (e.g., Jacobs et al., 2011; Arnold et al., 2013). These empirical results reveal that, for some localities at least, TT-OSL appear to produce reliable 
age estimates over timescales that would otherwise not be anticipated from existing lifetime calculations.

Regardless of discussions about the long-term stability of the TTOSL signal, the potential implications for our single-grain TT-OSL ages appear to be relatively unimportant. Closed cave chambers such as Sima de los Huesos represent ideal thermal environments for Middle Pleistocene TT-OSL applications because the temperature (and moisture) conditions are naturally regulated and remain effectively constant over diurnal, seasonal and annual timescales. Present-day temperatures inside the deeper chambers of Cueva Mayor are characterised by a stable temperature of $\sim 10^{\circ} \mathrm{C}$ (MartinChivelet et al., 2011). If we assume that the laboratory lifetime measurements of Adamiec et al. (2010) are directly applicable to our samples, the expected TT-OSL age underestimation would only
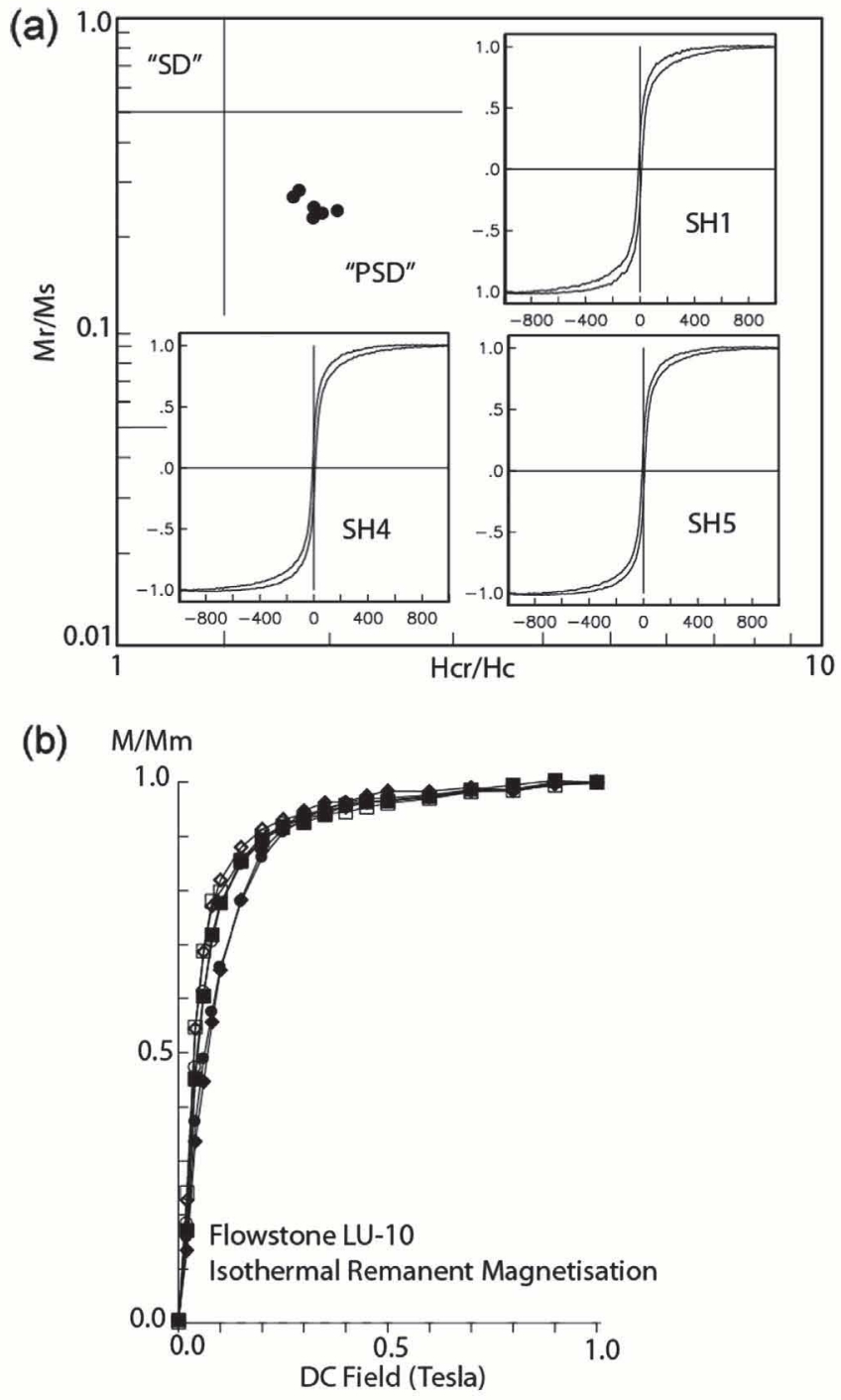

Figure 8. Rock-magnetic results from representative samples. (a) Hysteresis curves for three upper, lower and transitional upper-lower red clay samples, and 'Day plot' (Day et al., 1977). $\mathrm{Mr} / \mathrm{Ms}$ and $\mathrm{Hcr} / \mathrm{Hc}$ are the ratio of saturation remanence to saturation magnetisation, and the ratio of remanent coercive force to ordinary coercive force, respectively. All data points have $\mathrm{Mr} / \mathrm{Ms}$ ratios of about 0.5 , and $\mathrm{Hcr} / \mathrm{Hc}$ ratios of 2.0 , revealing magnetite in the pseudo-single domain (PSD) range. (b) Isothermal Remanent Magnetisation (IRM) acquisition curves for representative samples of flowstone LU-10. All curves show a very rapid acquisition of remanence up to $0.2 \mathrm{~T}$, and only a very slight increase up to $1 \mathrm{~T}$, indicating that magnetite is the main remanence carrier in the flowstone. amount to $\sim 4.7 \%$ according to the fractional loss equation of Aitken (1985:59). Moreover, this value would likely represent an uppermost estimate of long-term TT-OSL signal loss over the sample burial periods because average cave temperatures across the northern Iberian Peninsula are thought to have been lower during past glacial stages (e.g., Moreno et al., 2010). The difference between the measured weighted mean TT-OSL age for the café con leche sediments ( $416 \pm 19 \mathrm{ka})$ and the revised age obtained using a signal loss correction factor of $4.7 \%(436 \pm 21 \mathrm{ka})$ is statistically insignificant at $1 \sigma$. Given the similarity of these results, we can be reasonably confident that our existing single-grain TT-OSL ages are not masking any significant systematic biases arising from thermal instability.

In deriving a final TT-OSL age for the café con leche sediments we would favour the original, rather than corrected, weighted mean TT-OSL age of $416 \pm 19$ ka because there are insufficient constraints on the precision of the published lifetime estimates and on their direct applicability to our single-grain TT-OSL results. It is notable that the replicate pIR-IR 225 ages for all three of the café con leche samples are consistent with both the original TT-OSL ages and the revised TT-OSL ages obtained using an additional thermal stability correction. All things being equal, these results would support our earlier contention that an empirical fading correction does not appear to be necessary for the pIR-IR 225 signals of these samples. Obtaining replicate ages using two independent luminescence signals therefore provides a useful additional check on dating reliability in this study.

The replicate single-grain TT-OSL ages and pIR-IR 225 ages for the capping clay breccia (sample $\mathrm{SH} 12-4 \mathrm{~A}$ ) are indistinguishable, and are also in agreement with the luminescence ages obtained for the underlying café con leche deposits. Taken at face value, the correspondence between the café con leche and the capping clay breccia ages might appear contradictory given that the latter sediments overlie a prominent flowstone that has been previously dated to 18-68 ka (Bischoff et al., 1997). However, the older thanexpected ages for SH12-4A are consistent with the common sedimentological properties of these two yellowish brown clay horizons and the latest lithostratigraphic interpretations, which confirm a shared origin for the two deposits. As detailed in Arsuaga et al. (submitted), the capping clay breccia is not thought to represent a new infilling event of allochthonous sediments sourced directly from outside the cave. Instead, the matrix originates from internal reworking of café con leche sediments that had previously accumulated as chimney 'plugs' during the original high-energy debris flow event (i.e., LU-7). Sometime after the formation of the colada flowstone at $\sim 18-68 \mathrm{ka}$, these café con leche chimney accumulations fell (by gravity) onto the floor of the Sima ramp, where they were consolidated to form the matrix of the capping clay breccia. The age equivalence obtained in the present study for the main café con leche horizon and the capping clay breccia would appear to confirm these sedimentological interpretations. The agreement between the replicate TT-OSL and $\mathrm{PIR}^{-\mathrm{IR}_{225}}$ ages for SH12-4A is also consistent with the suggestion that the capping clay breccia was re-transported and re-deposited within a closed cave system without being subjected to any daylight exposure. If this was not the case, the two luminescence dating signals would likely display markedly different residual $D_{\mathrm{e}}$ values on account of their distinctly different bleaching sensitivities. In effect, sample SH12-4A represents a homogeneously 'unbleached' sample; i.e., the burial event recorded by its natural luminescence signals pertains to the penultimate, rather than the most recent, erosion-transportation-deposition cycle. Sample SH12-4A serves as a useful example of how an understanding of site accumulation processes can be critical for accurately interpreting luminescence dating datasets in complex cave environments. 


\section{Contextualisation and implications of the new chronologies}

The bracketing ages obtained in this study using luminescence dating and palaeomagnetism constrain the hominin-bearing sediments at Sima to between $427 \pm 12$ and $\sim 780 \mathrm{ka}$. To place these new ages into a broader chronological context, we have summarised in Table 6 the reliable numerical and correlative ages published thus far for Sima de los Huesos. Two chronological techniques have previously been applied to the sedimentary facies lying below the capping colada flowstone, namely: (i) U-series dating of the ST-b (lower SRA-3) and ST-a (upper SRA-3) speleothems at exposure ST (Fig. 2) (Bischoff et al., 2003, 2007); and (ii) palaeomagnetic dating of the fossiliferous red clays, sterile red clays and basal sands and silts at SH(Area A), SH(Area B) and SRB (Parés et al., 2000). Generally speaking, the macro- and micro-faunal records of the café con leche and upper red clay breccia horizons do not permit well-constrained, unequivocal age assignation beyond that of the broader early or mid-Middle Pleistocene (Cuenca-Bescós et al., 1997; García et al.,
1997, García and Arsuaga, 2011); hence we have not included biochronological indicators in this age comparison.

The published U-series ages for the SRA-3 speleothem were originally presented as minimum age constraint on the underlying archaeological horizon. However, as already mentioned, recent excavations have revealed that this previous interpretation was incorrect and that the lower part of SRA-3 (ST-b) represents a significantly older generation of flowstone (LU-2) that actually underlies the lower red clays and the basal sands and silts (Arsuaga et al., submitted). Uranium series ages of $153 \pm 5 \mathrm{ka}$ to $281_{-23}^{+28} \mathrm{ka}$ were obtained on the upper part of SRA-3 using thermal-ionisation mass-spectrometry (TIMS) (Bischoff et al., 2003) (Table 6). The ages for this speleothem, which corresponds to flowstone LU-8 at SRA and overlies the café con leche horizon, are in good agreement with (i.e., younger than) the luminescence ages obtained in this study. A non-finite age of $>350$ ka was originally obtained for the lower part of SRA-3 speleothem using TIMS (Bischoff et al., 2003). This age estimate was subsequently revised upwards to a minimum age of

Table 6

Summary of the published chronologies obtained for different stratigraphic sections at Sima de los Huesos using numerical and correlative dating techniques.

\begin{tabular}{|c|c|c|c|c|c|}
\hline Deposit & Lithostratigraphic unit & Section & Dating method & Age (ka) & Reference \\
\hline Re-worked café con leche & LU-11 & SRM & Single-grain TT-OSL & $426 \pm 39$ & This study \\
\hline Clay breccia (bat guano) & & SRM & Multi-grain pIR-IRSL & $417 \pm 27$ & This study \\
\hline \multirow[t]{7}{*}{ Capping speleothem (Colada) } & LU-10 & SRB, SRM & Conventional ${ }^{14} \mathrm{C}$ & $17.8 \pm 0.1$ & Bischoff et al., 1997 \\
\hline & & & & $17.8 \pm 0.1$ & \\
\hline & & & & $17.4 \pm 0.1$ & \\
\hline & & & & $18.9 \pm 0.1$ & \\
\hline & & & & $18.3 \pm 0.1$ & \\
\hline & & & & $20.5 \pm 0.1$ & \\
\hline & & SRA & Palaeomagnetism & $<780(n=20)$ & This study \\
\hline \multirow[t]{8}{*}{ Colada - embedded fox bones } & LU-10 & SRB & Conventional ${ }^{14} \mathrm{C}$ (collagen) & $25.1 \pm 0.2$ & Bischoff et al., 1997 \\
\hline & & & & $25.4 \pm 0.2$ & \\
\hline & & & & $25.7 \pm 0.2$ & \\
\hline & & & & $25.0 \pm 0.2$ & \\
\hline & & & & $21.4 \pm 0.1$ & \\
\hline & & SRB & U-series (alpha spectrometry) & $37 \pm 1$ & Bischoff et al., 1997 \\
\hline & & & & $23 \pm 1$ & \\
\hline & & & & $26 \pm 1$ & \\
\hline \multirow[t]{2}{*}{ CVP flowstone } & LU-10 & SB(R16) & Conventional ${ }^{14} \mathrm{C}$ & $>39$ & Bischoff et al., 1997 \\
\hline & & SB(R16) & U-series (alpha spectrometry) & $68 \pm 6(n=6)$ & Bischoff et al., 1997 \\
\hline Speleothem interbedded in café con leche horizon & $\mathrm{LU}-8$ & SRA & Palaeomagnetism & $<780(n=3)$ & This study \\
\hline \multirow[t]{2}{*}{ Speleothem ST-c (upper portion of SRA-3) } & LU-8 & ST & U-series (TIMS) & $\begin{array}{c}153 \pm 5 \\
257_{-16}^{+16} \\
281_{-23}^{+28}\end{array}$ & Bischoff et al., 2003 \\
\hline & $\mathrm{LU}-8$ & ST & Palaeomagnetism & $<780(n=1)$ & This study \\
\hline \multirow[t]{7}{*}{ Café con leche clay breccia } & LU-7 & SRB, SRM & Single-grain TT-OSL & $396 \pm 35$ & This study \\
\hline & & & & $419 \pm 34$ & \\
\hline & & & & $429 \pm 32$ & \\
\hline & & SRB, SRM & Multi-grain pIR-IRSL & $430 \pm 25$ & This study \\
\hline & & & & $428 \pm 27$ & \\
\hline & & & & $441 \pm 25$ & \\
\hline & & SRT(K22) & Palaeomagnetism & $<780(n=7)$ & This study \\
\hline \multirow[t]{2}{*}{ Fossiliferous upper red clays } & LU-6 & $\mathrm{SH}(\mathrm{R} 17$ \& $\mathrm{T} 17)$ & Palaeomagnetism & $<780(n=28)$ & This study \\
\hline & & SRA, SH(Area B) & Palaeomagnetism & $<780(n=12)$ & Parés et al., 2000 \\
\hline Gradational upper-lower red clays & LU-5+LU-6 & SH(R11 \& 16) & Palaeomagnetism & $<780(n=15)$ & This study \\
\hline \multirow[t]{2}{*}{ Sterile lower red clays } & LU-5 & $\mathrm{SH}(\mathrm{T} 16)$ & Palaeomagnetism & $<780(n=6)$ & This study \\
\hline & & SRB & Palaeomagnetism & $<780$ or $>780(n=4)$ & Parés et al., 2000 \\
\hline Sterile sands and silts & LU-3 & SH(Area A) & Palaeomagnetism & $>780 ?(n=5)$ & Parés et al., 2000 \\
\hline \multirow[t]{9}{*}{ Speleothem ST-b (lower portion of SRA-3) } & $\mathrm{LU}-2$ & ST & U-series (TIMS) & $290 \pm 25$ & Bischoff et al., 2003 \\
\hline & & & & $>350(n=9)$ & \\
\hline & & ST & U-series (MC ICP-MS) & $>517$ & Bischoff et al., 2007 \\
\hline & & & & $>551$ & \\
\hline & & & & $>537$ & \\
\hline & & & & $>518$ & \\
\hline & & & & $>571$ & \\
\hline & & & & $>513$ & \\
\hline & LU-2 & ST & Palaeomagnetism & $>780 ?(n=6)$ & This study \\
\hline Speleothem ST-a & $\mathrm{LU}-2$ & ST & Palaeomagnetism & $>780 ?(n=2)$ & This study \\
\hline
\end{tabular}

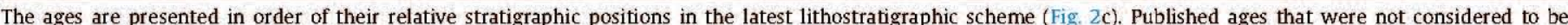

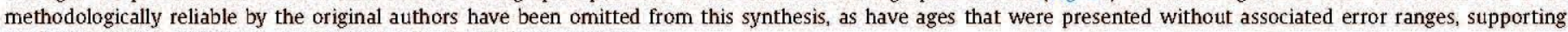
methodological descriptions, or specific details of sampling positions. 
$>530\left(600_{-66}^{+\infty}\right)$ ka following reanalysis of the same material using multi-collector inductively-coupled plasma mass-spectrometry (MC ICP-MS) (Bischoff et al., 2007) (Table 6). The latest U-series ages for the lower part of SRA-3, which range from $>517$ ka to $>571 \mathrm{ka}$, are in stratigraphic agreement with the luminescence ages obtained for the overlying café con leche horizon. Interpretation of these $U$-series ages as a reliable maximum age for the hominin fossils is made complicated by the close proximity of the ${ }^{230} \mathrm{Th} /{ }^{234} \mathrm{U}$ ratios to internal isotopic equilibrium, as is apparent from the large or non-finite upper error bounds. Since the existing U-series ages for the lower part of SRA-3 are effectively minimum ages, they do not provide any additional constraint on whether the normal polarity interval reported here for the LU-2 speleothem corresponds to the Brunhes Chron or to a shorter-lived intraMatuyama polarity subchron.

The palaeomagnetic results obtained in the present study for 70 sediment samples complement those published previously at Sima de los Huesos (Parés et al., 2000) and help to extend the spatial coverage of the original palaeomagnetic dataset to include the café con leche horizon and red clay horizons at several new exposures. Parés et al. (2000) reported a dominant normal polarity magnetisation for the upper red clays in Sima areas A and B, consistent with our results for this horizon. However, that study also reported traces of reversed magnetisation in some of the upper red clay samples, which suggested that additional magnetic acquisition could have taken place during one of several short-lived polarity subchrons within the Brunhes Chron (e.g., Channell et al., 2012). We do not see any traces of reversed polarity in our upper red clay samples, reinforcing the original interpretation of Parés et al. (2000) that the short duration of this reversal event (excursion or cryptochron), combined with the lower intensity of the geomagnetic field during the reversal phase, and prolonged diagenesis of the clays thereafter, are likely to have resulted in the preservation of reversed magnetisation in some samples but not in others. Moreover, the existence of localised areas of high porosity and concentrated water drainage in the Sima chamber would have also acted to restrict the zones displaying both normal and reversed magnetisation traces in the red clay horizon.

Four samples collected by Parés et al. (2000) towards the base of the non-fossiliferous lower red clays at exposure SRB produced stable, south and upwards (reversed polarity) magnetisation directions (Table 6). Palaeomagnetic results obtained in the present study from a higher stratigraphic position within the same unit (i.e., closer to the contact with the upper red clays) reveal exclusively normal polarities. There are several possible explanations for the apparent differences between these two sets of results: (i) spatial variations in the preserved dominant polarity related to locally variable drainage and porosity conditions in the Sima chamber, as detailed above; (ii) the basal part of the sterile lower red clays was deposited during the Matuyama Chron, i.e., before $780 \mathrm{ka}$, whereas the upper part of this horizon was deposited during the Brunhes Chron (with or without an intervening hiatus); or (iii) the sterile lower red clay horizon was deposited during the Middle Pleistocene period and records an intra-Brunhes reverse polarity event towards its base. Parés et al. (2000) also reported that the underlying sand and silt horizon preserved in Area A of the Sima chamber display a dominant reversed magnetisation (Table 6). The most conservative interpretation is that these sands and silts were deposited during the Matuyama Chron $>780 \mathrm{ka}$, since (i) the reversal is continuous and spans a significant vertical coverage of sediment accumulation $(\sim 90 \mathrm{~cm})$; and (ii) this unit is sedimentologically similar to a large sand body preserved in the nearby Sala de los Cíclopes, which is also of Matuyama age (Parés et al., 2010). Nevertheless, direct numerical dating of the lower red clays and the basal sand and silt deposits is required before this assertion can be confirmed.
In sum, the combined palaeomagnetic results from both the Parés et al. (2000) study and the current work provide a statistically significant sample dataset (11 exposures, 135 specimens) and confirm that the hominin-bearing red clays were deposited during the Brunhes Chron. In the absence of additional radiometric age control, however, it remains difficult to assign a definitive geomagnetic polarity chron to the underlying sediment horizons (lower red clays, sands and silts, white marls) and flowstones (LU2) (Fig. 2c).

The revised stratigraphic interpretations of the existing $U$-series ages (Bischoff et al., 2007) means that our new luminescence chronologies provide the first unequivocal minimum age control for the archaeological red clay horizon and the Sima hominin fossils. The stratigraphic relation between the luminescence ages and the archaeological horizon is well-constrained, since the samples were collected from spatially continuous sedimentary infills with a clear and direct association with the underlying archaeological clays. Our luminescence dating results for the café con leche horizon are both reproducible and precise, and are based on two consistent luminescence datasets from different types of mineral grains. The luminescence ages are also in good agreement with bracketing U-series ages for the upper part of SRA-3 (LU-8) and lower part of SRA-3 (LU-2). The robustness of the new ages for the archaeological horizon permits a more secure age assignation for the Sima hominin fossils, and enables more reliable comparisons with other penecontemporaneous ancestral Neanderthal remains from across Europe. In particular, the new minimum age of $427 \pm 12 \mathrm{ka}$ for the Sima fossils is younger than the $609 \pm 40 \mathrm{ka}$ age obtained for the $H$. heidelbergensis holotype at Mauer, Germany, using infrared radiofluorescence dating of bracketing sediments and combined ESR-U-series dating of herbivore teeth (Wagner et al., 2010). The difference between these two chronologies could be interpreted as being consistent with the more Neanderthal-derived morphologies (Arsuaga et al., 1991, 1993, 1997b) and dentition (Martinón-Torres et al., 2012) of the Sima fossils. However, our luminescence dating results provide minimum age constraint for the Sima fossils, and therefore do not necessarily preclude a broadly contemporaneous age for the two assemblages. The new age for the Sima fossils is also consistent with U-series ages of $>350 \mathrm{ka}$ obtained for speleothems overlying $H$. heidelbergensis cranial and mandibular remains at the cave site of Arago in France (Falguéres et al., 2004). Nonetheless, it is worth noting that the Arago ages are limited by internal isotopic equilibrium and they do not directly bracket the archaeological horizon, hence representing non-finite (minimum) ages for the associated $H$. heidelbergensis fossils. Subsequent attempts to refine the Arago age control using combined ESR-U-series dating of herbivore teeth from the main archaeological horizon have unfortunately proved problematic due to post-depositional geochemical alterations of the fossil-bearing sediments (Han et al., 2010).

The luminescence ages for the Sima fossils are slightly older than the ${ }^{40} \mathrm{Ar} /{ }^{39} \mathrm{Ar}$ age of $353 \pm 4 \mathrm{ka}$ obtained on a volcanoclastic layer found immediately above the Ceprano cranium (Nomade et al., 2011), which has been variously classified as a morphologically primitive example of $H$. heidelbergensis (e.g., Mounier et al., 2011) or a separate lineage that co-existed with $H$. heidelbergensis during the Middle Pleistocene (e.g., Manzi et al., 2001; Mallegni et al., 2003). Adding to the taxonomically diverse mosaic of Middle Pleistocene European hominin records is a recently dated mandible from Mala Balanica Cave, southern Serbia, which appears to lack derived Neanderthal features (Rakočević et al., 2011; Roksandic et al., 2011; Rink et al., 2013). Minimum ages of between 397 and $525 \mathrm{ka}$ have been obtained for this hominin mandible using luminescence (pIR-IR 225 ) dating of overlying sediments and combined ESR/U-series dating of teeth found above the 
hominin remains. The stratigraphic relationship between these dated samples and the associated mandible is comparable with that of our luminescence dating samples and the underlying Sima fossils. The minimum age estimate for the Balanica mandible overlaps with the new minimum ages for the Sima remains, indicating the potential co-existence of two distinct hominin lineages within different regions of Europe during the mid-Middle Pleistocene. We stress, however, that the Sima hominin morphology has been described for all skeletal parts, whereas the Balanica partial mandible is an incomplete fossil and should not be assigned the same taxonomic/phylogenetic value. Middle Pleistocene populations could have exhibited different combinations of primitive traits (for the modern human/Neaderthal clade) and different types of Neanderthal specialisations. The possibility remains, therefore, that the Balanica individual could have displayed Neanderthal autapomorphies in skeletal regions that were not preserved in the incomplete fossil record.

It is also interesting to compare the new ages for the Sima assemblage with the preserved archaeological history of other related sites within the Sierra de Atapuerca endokarstic complex. of particular interest is the Middle Pleistocene lithostratigraphic sequence at Gran Dolina (e.g., Carbonell et al., 1995; Bermúdez de Castro et al., 1997), which comprises five sedimentary units (TD711) with associated age control from combined ESR / U-series dating of ungulate teeth (Falguéres et al., 1999) and IRSL and thermoluminescence (TL) dating of polymineral sediments (Berger et al., 2008). Though lacking in hominin remains, TD10 preserves an extensive record of human activity beginning at $\sim 430 \pm 59 \mathrm{ka}$ (Berger et al., 2008) and continuing until $\sim 337 \pm 29$ ka (Falguéres et al., 1999) or $\mathbf{2 4 0} \pm \mathbf{4 4}$ ka (Berger et al., 2008). This important phase of hominin occupation at Gran Dolina is preceded by an apparent hiatus in the archaeological record from at least $780 \mathrm{ka}$ (TD7) to $480 \pm 130 \mathrm{ka}$ (TD9) (Berger et al., 2008), despite a semicontinuous sedimentary sequence being recorded during this time period. Our luminescence ages for the café con leche horizon at Sima de los Huesos are consistent with the combined ESR/Useries and TL ages obtained on the lower-middle horizons of TD10, suggesting that the two sedimentary fills were deposited broadly synchronously. The coeval nature of these two Middle Pleistocene deposits, and that of the fossiliferous red clay horizon at Sima de los Huesos, is also supported by their shared faunal and lithic records (e.g., Cuenca-Bescós et al., 2010; Rodríguez et al., 2011; Ollé et al., 2013). The similarities in the preserved lithostratigraphic record at Gran Dolina and apparent hiatus in the Middle Pleistocene archaeological record prior to $\sim \mathbf{4 8 0} \mathrm{ka}$ might suggest that the Sima hominin remains and the café con leche deposits were deposited in close temporal association, or even quasi-contemporaneously. In this sense, our minimum age estimates for the Sima fossils may approximate the actual depositional ages of the hominin remains. In the absence of more direct evidence, however, we maintain that the luminescence dating results should be considered as minimum ages for the Sima fossils. Further radiometric dating of the upper sedimentary layers at the nearby site of Sima de la Elefante is currently in progress and might help shed further light on potentially correlative occupation and sedimentary histories of the Atapuerca endokarst during the midMiddle Pleistocene. Direct luminescence dating of the fossilbearing red clays at Sima remains a challenge from a methodological perspective. However, successful isolation of suitably bleached silicate grains from this unit would also enable us to tighten the current maximum age limits on the Sima fossils.

The previously published minimum age estimate of $>530 \mathrm{ka}$ for Sima de los Huesos (Bischoff et al., 2007) received considerable attention vis-à-vis its perceived incompatibility with morphological and genetic evidence for hominin evolutionary divergences during the Middle Pleistocene (e.g., Endicott et al., 2010; Stringer, 2012). The revised stratigraphic interpretations of this U-series age presented earlier (and further detailed in Arsuaga et al., submitted) effectively negates any direct comparisons with existing genetic divergence estimates, since these $\mathbf{U}$-series results are now known to provide a non-finite maximum age estimate on the overlying fossils. However, it is worth considering whether our new luminescence ages fit with the latest phylogenetic and de novo predictions of hominin evolution. Molecular phylogenetic reconstructions of a population split between $H$. neanderthalensis and $H$. sapiens based on nuclear DNA sequencing were previously placed at between 270 and $\mathbf{4 4 0} \mathrm{ka}$ (Green et al., 2010). However, a recent revision of the nuclear mutation rate based on updated generation lengths for apes and improved generational mutation rates for modern humans (Langergraber et al., 2012) suggests that previous $H$. neanderthalensis $-H$. sapiens divergence estimates should be pushed back to somewhere on the order of 400-600 ka (Scally and Durbin, 2012) or even 423-781 ka (Langergraber et al., 2012). Phylogenetic estimates of the most recent common ancestor (MRCA) for $H$. neanderthalensis and $H$. sapiens lineages using complete mitochondrial DNA sequencing (Endicott et al., 2010) range from 315 to $506 \mathrm{ka}$ and 338 to $538 \mathrm{ka}$ assuming prior Homo-Pan calibration splits at 6-7 Ma and $6.5-7.5 \mathrm{Ma}$, respectively. The new minimum ages for the Sima hominins, which were ancestral to Neanderthals and display clear Neanderthal synapomorphies, are compatible with (i.e., potentially post-date) the updated population divergence and MRCA estimates of sometime between 315 to $781 \mathrm{ka}$ for the $H$. neanderthalensis and $H$. sapiens lineages. Considerable debate remains, however, over the suitability of existing taxonomic classifications, the nature of phylogenetic relationships and the spatio-temporal evolutionary histories of the Middle Pleistocene hominin record (e.g., Arsuaga et al., 1997b; Hublin, 2009; Endicott et al., 2010; Dennell et al., 2011; Stringer, 2012; Bermúdez de Castro and Martinón-Torres, 2013).

It is evident from the literature that relatively few of the Middle Pleistocene hominin remains across Europe have reliable numerical age control based on modern and widely accepted dating techniques. Out of the Middle Pleistocene sites that have been variously reported to contain $H$. heidelbergensis or ancestral Neanderthal assemblages, the list of undisputed, radiometrically dated localities is perhaps only limited to Mauer (Wagner et al., 2010), Sima de los Huesos (this study), Arago (Falguéres et al., 2004) and Ceprano (Nomade et al., 2011). From a geochronological perspective, appropriate caution must be exercised when making temporal comparisons with other Middle Pleistocene sites that have been dated using relative or correlative techniques (e.g., Roberts et al., 1994; Stringer and Hublin, 1999), or that have been dated using methodologies with potentially low reliability by present-day standards. Accurate interpretation of published ages for Middle Pleistocene hominin sites also requires due consideration of associated contextual information and chronological caveats, particularly for results that provide terminus ante quem (e.g., Falguéres et al., 2004) or terminus post quem age constraints on associated fossils, and results that are quoted as non-finite or even tentative ages due to methodological restrictions (e.g., Bischoff et al., 2003; Han et al., 2010). Overlooking this essential quality control information is likely to confuse rather than clarify the complex relationships in the Middle Pleistocene fossil record.

The paucity of wider numerical age control for key Middle Pleistocene fossil sites largely reflects the historical difficulties of dating this troublesome time period using traditional geochronological techniques. Recent advances in techniques such as uraniumlead dating $(\mathrm{U}-\mathrm{Pb})$ (e.g., Woodhead et al., 2006), cosmogenic burial dating (e.g., Carbonell, 2008; Balco and Shuster, 2009) and extended-range luminescence dating (e.g., Buylaert et al., 2012; 
Duller and Wintle, 2012) offer a new set of geochronological tools for redressing previous methodological limitations. The development of more widespread and reliable age control is critical for unravelling the evolutionary histories and phylogenetic relationships of the European Middle Pleistocene record. The new chronologies presented in this study for Sima de los Huesos demonstrate the versatility of TT-OSL and pIR-IR dating methods and highlight the potential role they could play in this endeavour.

\section{Conclusions}

To address uncertainties in existing chronological control at Sima de los Huesos, we have obtained new minimum age estimates for the hominin remains using two semi-independent extendedrange luminescence dating techniques. From this latest geochronological study, we can constrain the age of the café con leche clay breccia horizon to early MIS 11 or terminal MIS 12 and we are able to provide a combined minimum age estimate of $427 \pm 12 \mathrm{ka}$ for the underlying red clay breccia and its associated hominin remains. Our luminescence ages are internally consistent and support previous sedimentological interpretations that the café con leche horizon was deposited during a relatively short-lived, high-energy flooding episode. The very small natural residual doses ( $\sim 7 \mathrm{~Gy})$ measured for a modern analogue provide confidence that these sediments were adequately bleached by prolonged sunlight exposure prior to deposition inside the cave system. Our novel singlegrain TT-OSL approach has also provided additional insight into dating suitability at this potentially complex cave site, by enabling us to explicitly assess the extent of signal bleaching in the absence of multi-grain averaging influences. The consistency and reproducibility of our single-grain TT-OSL ages support the recent findings of Arnold et al. (2013) and demonstrate the broader potential of this approach for dating Middle Pleistocene deposits that contain suitably bright quartz grains.

New palaeomagnetic analyses undertaken at exposures within the main Sima chamber and along the Sima ramp reveal that the café con leche and upper red clay breccia were deposited during the Brunhes Chron, confirming the previous results of Parés et al. (2000). These correlative dating results provide a maximum age constraint of $\sim 780$ ka for the associated hominin fossils at Sima de los Huesos. Our new ages provide an important piece of the puzzle for reconstructing the complex history of the Sima hominin assemblage, and are compatible with the latest genetic predictions for a $H$. neanderthalensis $-H$. sapiens divergence sometime before $\sim 315 \mathrm{ka}$ and no earlier than $\sim 781 \mathrm{ka}$. However, there remains a clear need for more widespread and improved numerical chronology at other penecontemporaneous sites to better resolve the evolutionary history and phylogenetic relationships of the European Middle Pleistocene hominin fossil record.

\section{Acknowledgements}

Financial support for this research was provided by grant CGL2010-16821 awarded to J.M.P., L.A. and M.D. from the Ministerio de Economía y Competitividad de España (Plan Nacional de I + D + i 2008-2011), by project GL2012-38434-C03 awarded to J.L.A. and A.A., and by a Marie Curie International Reintegration Grant (PIRG08-GA-2010-276810) awarded to M.D. within the 7th European Community Framework Programme. L.A. and M.D. thank Carlos Pérez Garrido for his assistance with preparing and measuring the luminescence dating samples. We also thank the multidisciplinary research team of the Sierra de Atapuerca (EIA) for scientific and logistic support. Site access and permission to collect samples at Atapuerca was granted by the Junta de Castilla y León. L.A. and M.D. are grateful to Sébastien Huot (Université du Québec à
Montréal) for providing an Excel package to calculate K-feldspar fading rates. C. Mac Niocaill and an anonymous reviewer are thanked for their constructive comments on this paper.

\section{Appendix A. Supplementary material}

Supplementary material related to this article can be found at http://dx.doi.org/10.1016/j.jhevol.2013.12.001.

\section{References}

Adamiec, G., Duller, G.A.T., Roberts, H.M., Wintle, A.G., 2010. Improving the TT-OSI SAR protocol through source trap characterisation. Radiat. Meas. 45, 768-777. Aitken, M.J., 1985. Thermoluminescence Dating. Academic Press, London.

Aitken, M.J., 1998. An Introduction to Optical Dating: The Dating of Quaternary Sediments by the Use of Photon-Stimulated Luminescence, Oxford University Press, Oxford.

Alappat, L., Tsukamoto, S., Singh, P., Srikanth, D., Ramesh, R., Frechen, M., 2010. Chronology of Cauvery Delta sediments from shallow subsurface cores using elevated temperature post-IR IRSL dating of feldspar. Geochronometria 37, 37-47.

Armitage, S.J., Jasim, S.A., Marks, A.E., Parker, A.G., Usik, V.I., Uerpmann, H.-P., 2011. The southern route 'out of Africa': evidence for an early expansion of modern humans into Arabia. Science 331, 453-456.

Arnold, L.J., Roberts, R.G., 2009. Stochastic modelling of multi-grain equivalent dose (De) distributions: implications for OSL dating of sediment mixtures. Quatern Geochronol. 4, 204-230.

Arnold, L.., Roberts, R.G., 2011. Paper I - Optically stimulated luminescence (OSL) dating of perennially frozen deposits in north-central Siberia: OSL characteristics of quartz grains and methodological considerations regarding their suitability for dating. Boreas 40, 389-416.

Arnold, L. J. Bailey, R.M., Tucker, G.E., 2007. Statistical treatment of fluvial dose distributions from southern Colorado arroyo deposits. Quatern Geochronol. 2,162-167.

Arnold, L.J., Roberts, R.G., Galbraith, R.F., DeLong, S.B., 2009. A revised burial dose estimation procedure for optical dating of young and modern-age sediments. Quatern. Geochronol, 4, 306-325.

Arnold, L.J., Demuro, M., Navazo Ruiz, M., 2012a. Empirical insights into multi-grain averaging effects from 'pseudo' single-grain OSL measurements. Radiat. Meas. 47, $652-658$.

Arnold, L.]., Duval, M., Falguères, C, Bahain, J.-J., Demuro, M., 2012b. Portable gamma spectrometry with cerium-doped lanthanum bromide scintillators: suitability assessments for luminescence and electron spin resonance dating applications. Radiat. Meas. 47, 6-18.

Arnold, L.., Demuro, M., Navazo Ruiz, M., Benito-Calvo, A., Pérez-González, A., 2013. OSL dating of the Middle Palaeolithic Hotel California site, Sierra de Atapuerca north-central Spain. Boreas 42, 285-305.

Arsuaga, J.L., Carretero, J.M., Martinez, 1., Gracia, A., 1991. Cranial remains and long bones from Atapuerca/Ibeas (Spain). J. Hum. Evol. 20, 191-230.

Arsuaga, J.L., Martinez, I., Gracia, A., Carretero, J.M., Carbonell, E., 1993. Three new human skulls from the Sima de los Huesos site in Sierra de Atapuerca, Spain. Nature $362,534-537$.

Arsuaga, J.L., Martínez, I., Gracia, A., Carretero, J.M., Lorenzo, C., García, N. Ortega, A.I., 1997a. Sima de los Huesos (Sierra de Atapuerca, Spain). The site J. Hum. Evol. 33, 109-127.

Arsuaga, J.L., Martinez, I., Gracia, A., Lorenzo, C, Garcia, N., 1997b. The Sima de los Huesos crania (Sierra de Atapuerca, Spain), a comparative study. J. Hum. Evol. $33,219-281$.

Arsuaga, J.L., Carretero, J.M., Lorenzo, C., Gracia, A., Martínez, I., Bermúdez de Castro, J. Carbonell, E., 1997c. Size variation in Middle Pleistocene humans. Science 277, 1086-1088.

Arsuaga, J.L. Gracia, A., Lorenzo, C, Martinez, L., Pérez, P.J., 1999. Resto cranial humano de Galeria/Cueva de los Zarpazos (Sierra de Atapuerca, Burgos). In: Carbonell, E., Rosas, A., Diez, J.C. (Eds.), Atapuerca: ocupaciones humanas y paleoecología del yacimientos de Galería. Arqueología en Castilla y León 7. Junta de Castilla y Leon, Zamora, pp. 233-235.

Arsuaga, J.L., Aranburu, A., Arnold, LJ., Sharp, W.D., Falguères, C., Bischoff, J., Parés, J.M., Demuro, M., Sala, N., García, N., Cuenca-Bescos, G., Martínez, I., Gracia, A., Moreno, D., Shen, C.C., Ortega, A.I., Carbonell, E., Bermûdez de Castro, J.M., submitted. A new age for the Sima de los Huesos hominins. Science.

Auclair, M., Lamothe, M., Huot, S., 2003. Measurement of anomalous fading for feldspar IRSL using SAR. Radiat. Meas. 37, 487-492.

Bailey, R.M., Arnold, L.J., 2006. Statistical modelling of single grain quartz De distributions and an assessment of procedures for estimating burial dose. Quatern. Sci. Rev. 25, 2475-2502.

Balco, G., Shuster, D.L., 2009. ${ }^{26} \mathrm{Al}-{ }^{10} \mathrm{Be}-{ }^{21} \mathrm{Ne}$ burial dating. Earth Planet. Sci. Lett. $286,570-575$.

Banerjee, D., Murray, A.S., Bøtter-Jensen, L., Lang, A., 2001. Equivalent dose estimation using a single aliquot of polymineral fine grains. Radiat. Meas. 33 , $73-94$.

Benito-Calvo, A., Pérez-Gonzâlez, A., Parés, J.M., 2008. Quantitative reconstruction of Late Cenozoic landscapes: a case study in the Sierra de Atapuerca (Burgos, Spain). Earth Surf. Proc. Land. 33, 196-208. 
Berger, G.W., Pérez-González, A., Carbonell, E., Arsuaga, J.L., Bermûdez de Castro, J.M., Ku, T.-L, 2008. Luminescence chronology of cave sediments at the Ata puerca paleoanthropological site, Spain. J. Hum. Evol. 55, 300-311.

Bermúdez de Castro, J.M., Martinón-Torres, M., 2013. A new model for the evolution of the human Pleistocene populations of Europe. Quatern. Int. 295, 102-112.

Bermûdez de Castro, J.M., Arsuaga, J.L., Carbonell, E., Rosas, A., Martínez, I., Mosquera, M., 1997. A hominid from the Lower Pleistocene of Atapuerca, Spain: possible ancestor to Neandertals and modern humans. Science 276, 1392-1395.

Bermûdez de Castro, J.M., Carbonell, E., Cáceres, I., Díez, J.C., Fernández-Jalvo, Y, Mosquera, M., Ollé, A., Rodríguez, J., Rodríguez, X.P., Rosas, A., Rosell, J., Sala, R. Vergés, J.M., Made, J. van der, 1999. The TD6 (Aurora Stratum) hominid site. Final remarks and new questions. J. Hum. Evol. 37, 695-700.

Bermûdez de Castro, J.M., Martinón-Torres, M., Lozano, M., Sarmiento, S., Muela, A. 2004. Paleodemography of the Atapuerca-Sima de los Huesos hominin sample: a revision and new approaches to the paleodemography of the European Middle Pleistocene population. J. Anthropol. Res. 60, 5-26.

Bischoff, J.L, Fitzpatrick, J.A., León, L, Arsuaga, J.L, Falguéres, C, Bahain, J.J. Bullen, T., 1997. Geology and preliminary dating of the hominid-bearing sedimentary fill of the Sima de los Huesos Chamber, Cueva Mayor of the Sierra de Atapuerca, Burgos, Spain. J. Hum. Evol. 33, 129-154.

Bischoff, J.L., Shamp, D.D., Aramburu, A., Arsuaga, J.L., Carbonell, E., Bermûdez de Castro, J.M., 2003. The Sima de los Hueso hominids date to beyond U/Th equilibrium $(>350 \mathrm{kyr})$ and perhaps to $400-500 \mathrm{kyr}$ : new radiometric dates. J. Archaeol. Sci. 30, 275-280.

Bischoff, J.L., Williams, R.W., Rosenbauer, R.J., Aramburu, A., Arsuaga, J.L., García, N. Cuenca-Bescós, G., 2007. High-resolution U-series dates from the Sima de los Huesos hominids yields $600_{-66}^{+\infty}$ kyrs: implications for the evolution of the early Neanderthal lineage. J. Archaeol. Sci. 34, 763-770.

Bosák, P., Pruner, P., 2011. Magnetic Record in Cave Sediments: A Review. IAGA Special Sopron Book Series.

Bøtter-Jensen, L., Mejdahl, M., 1988. Assessment of beta dose-rate using a GM multicounter system. Nucl. Tracks Rad. Meas. 14, 187-191.

Bouzouggar, A., Barton, N., Vanhaeren, M., d'Errico, F., Collcutt, S., Higham, T. Hodge, E., Parfitt, S., Rhodes, E., Schwenninger, J.-L., Stringer, C., Turner, E. Ward, S., Moutmir, A., Stambouli, A., 2007. 82,000-year-old shell beads from North Africa and implications for the origins of modern human behavior. Proc. Natl. Acad. Sci. 104, 9964-9969.

Bowler, J.M., Johnston, H., Olley, J.M., Prescott, J.R, Roberts, R.G., Shawcross, W., Spooner, N.A., 2003. New ages for human occupation and climate change at Lake Mungo, Australia. Nature 421, 837-840.

Brennan, B.J., 2003. Beta doses to spherical grains. Radiat. Meas. 37, 299-303.

Buylaert, J.-P., Murray, A.S., Thomsen, K.J., Jain, M., 2009. Testing the potential of an elevated temperature IRSL signal from K-feldspar. Radiat. Meas, 44, 560-565.

Buylaert, J.-P., Thiel, C., Murray, A.S., Vandenberghe, D.A.G., Yi, S., Lu, H., 2011. IRSL and post-IR IRSL residual doses recorded in modern dust samples from the Chinese loess plateau. Geochronometria 38, 432-440.

Buylaert, J.-P., Jain, M., Murray, A.S., Thomsen, K.J., Thiel, C., Sohbati, R., 2012. A robust feldspar luminescence dating method for Middle and Late Pleistocene sediments. Boreas 41, 435-451.

Carbonell, E., Bermûdez de Castro, J.M., Arsuaga, J.L, Díez, J.C., Rosas, A., CuencaBescós, G., Sala, R., Mosquera, M., Rodriguez, X.P., 1995. Lower Pleistocene hominids and artifacts from Atapuerca-TD6 (Spain). Science 269, 826-830.

Carbonell, E., Bermûdez De Castro, J.M., Parés, J.M., Pérez-González, A., CuencaBescós, G., Olle, A., Mosquera, M., Huguet, R., Made, J. van der, Rosas, A., Sala, R. Vallverdû, J., García, N., Granger, D.E., Martinón-Torres, M., Rodríguez, X.P. Stock, G.M., Vergès, J.M., Allué, E., Burjachs, F., Cáceres, I., Canals, A., Benito, A. Díez, C, Lozano, M., Mateos, A., Navazo, M., Rodríguez, J., Rosell, J., Arsuaga, J.L. 2008. The first hominin of Europe. Nature $452,465-470$.

Channell, J.E.T., Hodell, D.A., Curtis, J.H., 2012. ODP Site 1063 (Bermuda Rise) revisited: oxygen isotopes, excursions and paleointensity in the Brunhes Chron Geochem. Geophys. Geosyst. 13, Q02001.

Cuenca-Bescós, G., Laplana Conesa, C, Canudo, J.I. Arsuaga, J.L, 1997. Small mammals from Sima de los Huesos. J. Hum. Evol. 33, 175-190.

Cuenca-Bescós, G., Rofes, J., López-García, J.M., Blain, H.A., De Marfâ, R.J., GalindoPellicena, M.A., Bennásar-Serra, M.L., Melero-Rubio, M., Arsuaga, J.L., Bermúdez de Castro, J.M., Carbonell, E., 2010. Biochronology of Spanish Quaternary small vertebrate faunas. Quatern. Int. 212, 109-119.

Day, R., Fuller, M. Schmidt, V.A., 1977. Hysteresis properties of titanomagnetites: grain-size and compositional dependence. Phys. Earth Planet. In. 13, 260-267.

Demuro, M., Roberts, R.G., Froese, D.G., Arnold, L.J., Brock, F., Bronk Ramsey, C., 2008 Optically stimulated luminescence dating of single and multiple grains of quartz from perennially frozen loess in western Yukon Territory, Canada: comparison with radiocarbon chronologies for the late Pleistocene Dawson tephra. Quatern. Geochronol. 3, 346-364.

Demuro, M., Arnold, L.., Froese, D.G., Roberts, R.G., 2013. OSL dating of loess deposits bracketing Sheep Creek tephra beds, northwest Canada: dim and problematic single-grain OSL characteristics and their effect on multi-grain age estimates, Quatern. Geochronol. 15, 67-87.

Dennell, R.W., Martinón-Torres, M., Bermûdez de Castro, J.M., 2011. Hominin vari ability, climatic instability and population demography in Middle Pleistocene Europe, Quatern. Sci. Rev. 30, 1511-1524.

Duller, G.A.T., 2003. Distinguishing quartz and feldspar in single grain luminescence measurements. Radiat. Meas. 37, 161-165.

Duller, G.A.T., 2008. Single-grain optical dating of Quaternary sediments: why aliquot size matters in luminescence dating. Boreas 37, 589-612.
Duller, G.A.T., Wintle, A.G., 2012. A review of the thermally transferred optically stimulated luminescence signal from quartz for dating sediments. Quatern. Geochronol. 7, 6-20.

Endicott, P., Ho, S.Y.W., Stringer, C.B., 2010. Using genetic evidence to evaluate four palaeoanthropological hypotheses for the timing of Neandertal and modern human origins. J. Hum. Evol. 59, 87-95.

Falguéres, C., Bahain, J.J. Yokoyama, Y. Arsuaga, J.L., Bermûdez de Castro, J.M. Carbonell, E., Bischoff, J.L., Dolo, J.M., 1999. Earliest humans in Europe: the age of TD6 Gran Dolina, Atapuerca, Spain. J. Hum. Evol, 33, 343-352.

Falguéres, Y., Yokoyama, G., Shen, J.L., Bischoff, J.L., Ku, Y.-L, de Lumley, H., 2004. New U-series dates at the Caune de l'Arago, France. J. Archaeol. Sci. 31, 941-952.

Fattahi, M., Stokes, S., 2000. Extending the time range of luminescence dating using red TL (RTL) from volcanic quartz. Radiat. Meas. 32, 479-485.

Feathers, J.K., Casson, M.A., Schmidt, A.H., Chithamboet, M.L., 2012. Application of pulsed OSL to polymineral fine-grained samples. Radiat. Meas. 47, 201-209.

Fisher, R.A., 1953. Dispersion on a sphere. Proc. R. Soc. A 217, 295-305.

Galbraith, R.F. Green, P.F. 1990. Estimating the component ages in a finite mixture. Nucl. Tracks Rad. Meas. 17, 197-206.

Galbraith, R.F., Roberts, R.G., Laslett, G.M., Yoshida, H., Olley, J.M., 1999. Optical dating of single and multiple grains of quartz from Jinmium rock shelter, northern Australia: Part I, experimental design and statistical models. Archaeometry 41, 339-364.

Garcia, N., Arsuaga, J.L, 2011. The Sima de los Huesos (Burgos, northern Spain): palaeoenvironment and habitats of Homo heidelbergensis during the Middle Pleistocene. Quatern. Sci. Rev. 30, 1413-1419.

García, N., Arsuaga, J.L., Torres, T., 1997. The carnivore remains from the Sima de los Huesos Middle Pleistocene site (Sierra de Atapuerca, Spain). J. Hum. Evol. 33, 155-174.

Gliganic, L.A., Jacobs, Z., Roberts, R, 2012a. Luminescence characteristics and dose distributions for quartz and feldspar grains from Mumba rockshelter, Tanzania. Archaeol. Anthropol. Sci. 4, 115-135.

Gliganic, L.A., Jacobs, Z., Roberts, R.G., Domínguez-Rodrigo, M., Mabulla, A.Z.P., 2012b. New ages for Middle and Later Stone Age deposits at Mumba rockshelter, Tanzania: optically stimulated luminescence dating of quartz and feldspar grains. J. Hum Evol. 62, 533-547.

Green, R.E., Krause, J., Briggs, A.W., Maricic, T., Stenzel, U., Kircher, M., Patterson, N., Li, H., Zhai, W., His-Yang Fritz, M., Hansen, N.F., Durand, E.Y., Malaspinas, A.-S., Jensen, J.D., Marques-Bonet, T., Alkan, C., Prüfer, K., Meyer, M., Burbano, H.A., Good, J.M., Schultz, R., Aximu-Petri, A., Butthof, A., Höber, B., Höffner, B., Siegemund, M. Weihmann, A., Nusbaum, C. Lander, E.S., Russ, C., Novod, N., Affourtit, J., Egholm, M., Verna, C., Rudan, P., Brajkovic, D., Kucan, Z., Gusic, I., Doronichev, V.B., Golovanova, L., Lalueza-Fox, C., de la Rasilla, M., Fortea, J., Rosas, A., Schmitz, R.W., Johnson, P.LF., Eichler, E.E., Falush, D., Birney, E., Mullikin, J.C., Slatkin, M., Nielsen, R., Kelso, J., Lachmann, M., Reich, D., Pääbo, S., 2010. A draft sequence of the Neandertal genome. Science 328, 710-722.

Guérin, G., Mercier, M., Adamiec, G., 2011. Dose-rate conversion factors: update. Ancient TL 29, 5-8.

Guérin, G., Murray, A.S., Jain, M., Thomsen, K.J., Mercier, N., 2013. How confident are we in the chronology of the transition between Howieson's Poort and Still Bay? J. Hum. Evol. 64, 314-317.

Han, F., Falguères, C., Bahain, J.-J., Shao, Q., Duval, M., Lebon, M., Garcia, T., Dolo, J.M., Perrenoud, C., Shen, G.J., de Lumley, H., 2010. Effect of deposit alterations on the dating of herbivorous teeth from Arago cave by the ESR-U-series method. Quatern. Geochronol. 5, 376-380.

Hublin, J.-I., 2009. The origin of Neanderthals. Proc. Natl. Acad. Sci. 106, 1602216027

Huntley, D.J., Baril, M.R., 1997. The K content of the K-feldspars being measured in optical dating or in thermoluminescence dating. Ancient TL 15, 11-13.

Huntley, D.J., Clague, J.J., 1996. Optical dating of tsunami-laid sands. Quatern. Res. $46,127-140$.

Huntley, D.J., Hancock, R.G.V., 2001. The Rb contents of the K-feldspar grains being measured in optical dating. Ancient TL 19, 43-46.

Huntley, D.J., Lamothe, M., 2001. Ubiquity of anomalous fading in K-feldspars and the measurement and correction for it in optical dating. Can. J. Earth. Sci. 38, 1093-1106.

Huntley, D.J., Lian, O.B., 1999. Using optical dating to determine when a sediment was last exposed to sunlight In: Lemmen, D.S., Vance, R.E. (Eds.), Holocene Climate and Environmental Change in the Palliser Triangle: A Geoscientific Context for Evaluating the Impacts of Climate Change on the Southern Canadian Prairies, Geological Survey of Canada, Ottawa, Bulletin, vol. 534, pp. 211-222.

Huot, S., Buylaert, J.P., Murray, A.S., 2006. Isothermal thermoluminescence signals from quartz. Radiat. Meas. 41, 796-802.

Jacobs, Z., Duller, G.A.T., Wintle, A.G., 2006. Interpretation of single-grain De distributions and calculation of $D_{e}$, Radiat. Meas, 41, 264-277.

Jacobs, Z., Wintle, A.G., Roberts, R.G., Duller, G.A.T., 2008. Equivalent dose distributions from single grains of quartz at Sibudu, South Africa: context, causes and consequences for optical dating of archaeological deposits. J. Archaeol. Sci. 35 , $1808-1820$.

Jacobs, Z., Roberts, R.G., Lachlan, T.J., Karkanas, P., Marean, C.W., Roberts, D.L., 2011. Development of the SAR TT-OSL procedure for dating Middle Pleistocene dune and shallow marine deposits along the Cape coast of South Africa. Quatern. Geochronol. 6, 491-513.

Jain, M., Duller, G.A.T., Wintle, A.G., 2007. Dose response, thermal stability and optical bleaching of the $310^{\circ} \mathrm{C}$ isothermal TL signal in quartz. Radiat. Meas. 42 , 1285-1293. 
Kang, S., Lu, Y., Wang, X.L, 2011. Closely-spaced recuperated OSL dating of the last interglacial paleosol in the southeastern margin of the Chinese Loess Plateau. Quatern. Geochronol. 6, 480-490.

Kars, R.H., Busschers, F.S., Wallinga, J., 2012. Validating post IR-IRSL dating on Kfeldspars through comparison with quartz OSL ages. Quatern. Geochronol. 12, $74-86$.

Kirschvink, J.L., 1980. The least-squares line and plane and the analysis of paleomagnetic data. Geophys. J. Roy. Astron. Soc. 62, 699-718.

Lang, A., Wagner, G.A., 1997. Infrared stimulated luminescence dating of Holocene colluvial sediments using the $410 \mathrm{~nm}$ emission. Quatern. Sci. Rev. 16, 393-396.

Lang, A., Hatté, C, Rousseau, D.D., Antoine, P., Fontugne, M., Zöller, L., Hambach, U. 2003. High-resolution chronologies for loess: comparing AMS $14 \mathrm{C}$ and optical dating results. Quatern. Sci. Rev. 22, 953-959.

Langergraber, K.E. Prüfer, K. Rowney, $C_{\text {, }}$ Boesch, $C_{n}$, Crockford, $C$, Fawcett, $K$. Inoue, E., Inoue-Muruyama, M., Mitani, J.C., Muller, M.N., Robbins, M.M., Schubert, G., Stoinski, T.S., Viola, B., Watts, D., Wittig, R.M., Wrangham, R.W. Zuberbühler, K., Pääbo, S., Vigilant, L, 2012. Generation times in wild chimpanzees and gorillas suggest earlier divergence times in great ape and human evolution. Proc. Natl. Acad. Sci. 109, 15716-15721.

Latham, A.G., Ford, D.C. 1993. The paleomagnetism and rock magnetism of cave and karst deposits. In: Applications of Paleomagnetism to Sedimentary Geology. SEPM Special Publication, vol. 49, pp. 149-155.

Li, B., Li, S.-H., 2012. Luminescence dating of Chinese loess beyond $130 \mathrm{ka}$ using the non-fading signal from K-feldspar, Quatern. Geochronol. 10, 24-31.

Lisiecki, L.E., Raymo, M.E., 2005. A Pliocene-Pleistocene stack of 57 globally distributed benthic $\delta^{18} \mathrm{O}$ records. Paleoceanography 20. PA 1003.

Lorenzo, C, Carretero, J.M., Arsuaga, J.L, Gracia, A., Martínez, L, 1998. Intrapopulational body size variation and cranial capacity variation in Middle Pleistocene humans: the Sima de los Huesos sample (Sierra de Atapuerca, Spain). Am. J. Phys. Anthropol. 106, 19-33.

Lowick, S.E., Trauerstein, M., Preusser, F., 2012. Testing the application of post IRIRSL dating to fine grain waterlain sediments. Quatern. Geochronol. 8, 33-40.

Mallegni, F., Carnieri, C., Bisconti, M., Tartarelli, G., Ricci, S., Biddittu, I., Segre, A. 2003. Homo cepranensis sp. nov. and the evolution of African-European Middle Pleistocene hominids. C. R. Palevol 2, 153-154

Manzi, G., Mallegni, F., Ascenzi, A., 2001. A cranium for the earliest Europeans: phylogenetic position of the hominid from Ceprano, Italy. Proc. Natl. Acad. Sci. 9, $10011-10016$.

Martín-Chivelet, J. Muñ̃oz-García, M.B., Edwards, R.L., Turrero, M.J., Ortega, A.L. 2011. Land surface temperature changes in Northern Iberia since 4000 yr BP, based on $813 \mathrm{C}$ of speleothems. Global Planet Change 77, 1-12.

Martinón-Torres, M., Bastir, M., Bermúdez de Castro, J.M. Gómez, A., Sarmiento, S. Muela, A., Arsuaga, J.L, 2006. Hominin lower second premolar morphology: evolutionary inferences through geometric morphometric analysis. J. Hum Evol. 50, 523-533.

Martinón-Torres, M., Bermûdez de Castro, J.M., Gớmez-Robles, A., Prado-Simón, L. Arsuaga, J.L., 2012. Morphological description and comparison of the dental remains from Atapuerca-Sima de los Huesos site (Spain). J. Hum. Evol. 62, 7-58.

Mejdahl, V., 1979. Thermoluminescence dating: beta-dose attenuation in quartz grains. Archaeometry 21, 61-72.

Mejdahl, V., 1987. Internal radioactivity in quartz and feldspar grains. Ancient TL 5 10-17.

Moreno, A., Stoll, H., Jiménez-Sánchez, M., Cacho, I., Valero-Garcés, B., Ito, E. Edwards, R.L., 2010. A speleothem record of glacial (25-11.6 kyr BP) rapid climatic changes from northern Iberian Peninsula. Global Planet. Change 71, 218231.

Moreno, D., Falguêres, C., Pérez-González, A., Duval, M., Voinchet, P., BenitoCalvo, A., Ortega, A.I., Bahain, J.-J. Sala, R, Carbonell, E., Bérmudez de Castro, J.M., Arsuaga, J.L., 2012. ESR chronology of alluvial deposits in the Arlanzón valley (Atapuerca, Spain): contemporaneity with Atapuerca Gran Dolina site, Quatern. Geochronol, 10, 418-423.

Mounier, A., Condemi, S., Manzi, G., 2011. The stem species of our species. A place for the archaic human cranium from Ceprano, Italy. PLoS One 6, e18821.

Murray, A.S., Roberts, R.G., 1997. Determining the burial time of single grains of quartz using optically stimulated luminescence. Earth Planet. Sci. Lett. 152 $163-180$.

Murray, A.S., Wintle, A., 2000. Luminescence dating of quartz using an improved single-aliquot regenerative-dose protocol. Radiat. Meas. 32, 57-73.

Nomade, S., Muttoni, G., Guillou, H., Robin, E., Scardia, G., 2011. First ${ }^{40} \mathrm{Ar}{ }^{39} \mathrm{Ar}$ age of the Ceprano man (central Italy), Quatern. Geochronol. 6, 453-457.

Ollé, A., Mosquera, M., Rodríguez, X.P., de Lombera-Hermida, A., García-Antón, M.D., García-Medrano, P., Peña, L, Menéndez, L., Navazo, M., Terradillos, M. Bargalló, A. Márquez, B. Sala, R., Carbonell, E., 2013. The Early and Middle Pleistocene technological record from Sierra de Atapuerca (Burgos, Spain) Quatern. Int. 295, 138-167.

Olley, J.M., Caitcheon, G.G., Roberts, R.G., 1999. The origin of dose distributions in fluvial sediments, and the prospect of dating single grains of quartz from fluvial deposits using optically stimulated luminescence. Radiat. Meas. 30 207-217.

Olley, J.M. Pietsch, T., Roberts, R.G., 2004. Optical dating of Holocene sediments from a variety of geomorphic settings using single grains of quartz. Geomorphology 60, 337-358.

Ortega A.I. Benito-Calvo, A. Pérez-González, A, Martín Merino, M.A. Pérez Martínez, R., Parés, J.M., Aramburu, A., Arsuaga, J.L., Bermúdez de Castro, J.M., Carbonell, E., 2013. Evolution of multilevel caves in the Sierra de Atapuerca
Burgos, Spain) and its relation to human occupation. Geomorphology 196 $122-137$

Parés, J.M., Pérez-González, A., 1995. Paleomagnetic age for hominid fơssils at Atapuerca Archaeological site, Spain. Science 269, 830-832.

Parés, J.M., Perez-González, A., 1999, Magnetochronology and stratigraphy at Gran Dolina section, Atapuerca (Burgos, Spain). J. Hum. Evol. 37, 325-342.

Parés, J.M. Arsuaga, J.L. Pérez-González, A., Weil, A., 2000. On the age of the hominid fossils at the Sima de los Huesos, Sierra de Atapuerca: paleomagnetic evidence. Am. J. Phys. Anthropol. 111, 451-461.

Parés, J.M., Pérez-Gonzalez, A., Rosas, A., Benito, A., Bermûdez de Castro, J.M. Carbonell, E., Huget, R., 2006. Matuyama-Age Lithic Tools in the "Sima del Elefante" Site, Atapuerca (N Spain). J. Hum. Evol. 50, 163-169.

Parés, J.M., Pérez-Gonzalez, A., Arsuaga, J.L., Bermúdez de Castro, Carbonell, E. Ortega, A.I., 2010. Characterizing sedimentary history of cave deposits, using archaeomagnetism and rock magnetism, Atapuerca ( $N$ Spain). Archaeometry $52,882-898$.

Parés, J.M., Arnold, L., Duval, M., Demuro, M. Pérez-González, A., Bermúdez de Castro, J.M., Carbonell, E., Arsuaga, J.L, 2013. Reassessing the age of Atapuerca TD6 (Spain): new paleomagnetic results. J. Archaeol. Sci. 40, 4586-4595.

Pawley, S.M., Bailey, R.M., Rose, J., Moorlock, B.S.P. Hamblin, R.J.O., Booth. S.J. Lee, J.R., 2008. Age limits on Middle Pleistocene glacial sediments from OSI dating, north Norfolk, UK. Quatern. Sci. Rev, 27, 1363-1377.

Perkins, A.M., Maher, B.A., 1993. Rock magnetic and palaeomagnetic studies of British speleothems. J. Geomagn. Geolectr. 45, 143-153.

Petraglia, M., Korisettar, R., Boivin, N., Clarkson, C., Ditchfield, P., Jones, S., Koshy, J. Lahr, M.M., Oppenheimer, C., Pyle, D., Roberts, R., Schwenninger, J.L., Arnold, L, White, K., 2007. Middle Paleolithic assemblages from the Indian subcontinent before and after the Toba super-eruption. Science 317, 114-116.

Pickering, R., Jacobs, Z., Herries, A.I.R., Karkanas, P., Bar-Matthews, M., Woodhead, J.D., Kappen, P., Fisher, E., Marean, C.W., 2013. Paleoanthropologically significant South African sea caves dated to 1.1-1.0 million years using a combination of $\mathrm{U}-$ $\mathrm{Pb}$, TT-OSL and palaeomagnetism. Quatern. Sci. Rev. 65, 39-52.

Porat, N., Duller, G.A.T., Roberts, H.M., Wintle, A.G. 2009. A simplified SAR protocol for TT-OSL. Radiat. Meas. 44, 538-542.

Prescott, J.R., Hutton, J.T., 1994. Cosmic ray contributions to dose rates for luminescence and ESR dating: large depths and long-term time variations. Radiat. Meas. 23, 497-500.

Rakočevic, Z., Mihailovic, B., Guibert, P., Babb, J., 2011. A human mandible (BH-1) from the Pleistocene deposits of Mala Balanica cave (Sicevo Gorge, Niš, Serbia) J. Hum. Evol. 61, 186-196.

Readhead, M.L, 2002. Absorbed dose fraction for ${ }^{87} \mathrm{Rb} \beta$ particles. Ancient TL 20 $25-28$

Rees-Jones, J., 1995. Optical dating of young sediments using fine-grain quartz. Ancient TL 13, 9-14.

Rees-Jones, J. Tite, M.S. 1997. Optical dating results for British archaeological sediments. Archaeometry 39, 177-187.

Rink, W.J., Mercier, N., Mihailovic, D., Morley, M.W., Thompson, J.W., Roksandic, M., 2013. New radiometric ages for the BH-1 Hominin from Balanica (Serbia) implications for understanding the role of the Balkans in Middle Pleistocene human evolution. PLoS One 8, e54608.

Roberts, H.M., 2012. Testing Post-IR IRSL protocols for minimising fading in feld spars, using Alaskan loess with independent chronological control. Radiat Meas. 47, 716-724.

Roberts, M.B., Stringer, C.B., Parfitt, S.A., 1994. A hominid tibia from Middle Pleis tocene sediments at Boxgrove UK Nature $369,311-313$.

Rodríguez, J., Burjachs, F., Cuenca-Bescós, G., García, N., Made, J., van der, Pêrez González, A., Blain, H.-A., Expósito, L. López-Garca, J.M., García Antón, M. Allué, E., Cáceres, I., Huguet, R., Mosquera, M., ollé, A., Rosell, J., Parés, J.M. Rodríguez, X.P., Díez, C., Rofes, J., Sala, R., Saladié, P., Vallverdú, J., Bennasar, M.L. Blasco, R., Bermúdez de Castro, J.M., Carbonell, E., 2011. One million years of cultural evolution in a stable environment at Atapuerca (Burgos, Spain). Quatern. Sci. Rev. 30, 1396-1412.

Roksandic, M., Mihailović, D., Mercier, N., Dimitrijević, V., Morley, M.V. Rakočevic, Z, Guibert, P. Babb. J. 2011. A human mandible (BH-1) from the Pleistocene deposits of Mala Balanica cave (Sicevo Gorge, Niš, Serbia). J. Hum Evol. 61, 186-196

Rosas, A., 2001. Occurrence of Neanderthal features in mandibles from the Atapuerca-SH site. Am. J. Phys. Anthropol. 114, 74-91.

Scally, A., Durbin, R., 2012. Revising the human mutation rate: implications for understanding human evolution. Nat. Rev. Genet. 13, 745-753.

Singarayer, J.S., Bailey, R.M., Rhodes, E.J., 2000. Potential of the slow component of quartz OSL for age determination of sedimentary samples. Radiat. Meas. 32, 873-880.

Spooner, N.A., 1992. Optical dating: preliminary results on the anomalous fading of luminescence from feldspars. Quatern. Sci. Rev. 11, 139-145.

Spooner, N.A., 1994. The anomalous fading of infrared-stimulated luminescence from feldspars. Radiat. Meas. 23, 625-632.

Stevens, T., Buylaert, J.-P., Murray, A.S., 2009. Towards development of a broadly-applicable SAR TT-OSL dating protocol for quartz. Radiat. Meas. 44 639-645.

Stringer, C.B., 2012. The status of Homo heidelbergensis. Evol. Anthropol. 21, 101-107.

Stringer, C.B., Hublin, J.-I., 1999. New age estimates for the Swanscombe hominid and their significance for human evolution. J. Hum. Evol, 37, 873-877.

Sun, X.F., Mercier, N., Falgueres, C, Bahain, J.J., Despriee, J., Bayle, G., Lu, H.Y., 2010. Recuperated optically stimulated luminescence dating of middle-size quartz 
grains from the Palaeolithic site of Bonneval (Eure-et-Loir, France), Quatern. Geochronol. 5, 342-347.

Sun, X., Lu, H., Wang, S., Yi, S., Shen, C., Zhang, W., 2013. TT-OSL dating of Longyadong Middle Palaeolithic site and palecenvironmental implications from hominin occupation in Luonan Basin (central China). Quatern. Res. 79, 168-174.

Thiel, C., Buylaert, J.-P., Murray, A., Terhorst, B., Hofer, L, Tsukamoto, S., Frechen, M., 2011. Luminescence dating of the Stratzing loess profile (Austria) - Testing the potential of an elevated temperature post-IR IRSL protocol. Quatern. Int. 234, $23-31$.

Thiel, C. Buylaert, J.-P., Murray, A.S., Elmejdoub, N., Jedoui, Y., 2012. A comparison of TT-OSL and post-IR IRSL dating of coastal deposits on Cap Bon peninsula, northeastern Tunisia. Quatern. Geochronol. 10, 209-217.

Thomsen, K.J., Murray, A.S., Jain, M., Bøtter-Jensen, L., 2008. Laboratory fading rates of various luminescence signals from feldspar-rich sediment extracts. Radiat Meas, $43,1474-1486$.

Tsukamoto, S., Duller, G.A.T., Wintle, A.G., 2008. Characteristics of thermally transferred optically stimulated luminescence (TT-OSL) in quartz and its potential for dating sediments. Radiat. Meas. 43, 1204-1218.
Vasiliniuc, S. Vandenberghe, D.A.G. Timar-Gabor, A., Panaiotu, C., Cosma, C, van den Haute, P., 2012. Testing the potential of elevated temperature post-IR IRSL signals for dating Romanian loess. Quatern. Geochronol. 10, 75-80.

Wagner, G.A., Krbetschek, M. Degering, D. Bahain, J-J, Shao, Q, Falguêres, C. Voinchet, P., Dolo, J.-M., Garcia, T., Rightmire, G.P., 2010. Radiometric dating of the type-site for Homo heidelbergensis at Mauer, Germany. Proc. Natl. Acad. Sci. $107,19726-19730$.

Wang, X.L. Wintle, A.G., Lu, Y.C., 2006a. Thermally transferred luminescence in finegrained quartz from Chinese loess: basic observations. Radiat. Meas. 41, 649-658.

Wang, X.L., Lu, Y.C. Wintle, A.G., 2006b. Recuperated OSL dating of fine-grained quartz in Chinese loess. Quatern. Geochronol. 1, 89-100.

Woodhead, J., Hellstrom, J., Maas, R., Drysdale, R., Zanchetta, G., Devine, P., Taylor, E., 2006. U-Pb geochronology of speleothems by MC-ICPMS. Quatern. Geochronol. 1, 208-221.

Zijderveld, J.D.A., 1967. AC demagnetization of rocks: analysis of results. In: Collinson, D.W., Runcorn, S.K., Creer, K.M. (Eds.), Methods in Paleomagnetism. Elsevier, New York, pp. 254-286. 